\title{
An integrated view on monitoring and compensation for dynamic optical networks: from management to physical layer
}

\author{
A. Teixeira - L. Costa - G. Franzl - S. Azodolmolky • \\ I. Tomkos - K. Vlachos - S. Zsigmond · T. Cinkler • \\ G. Tosi-Beleffi - P. Gravey • T. Loukina • \\ J. A. Lázaro • C. Vazquez · J. Montalvo · E. Le Rouzic
}

\begin{abstract}
A vertical perspective, ranging from management and routing to physical layer options, concerning dynamic network monitoring and compensation of impairments $(\mathrm{M} \& \mathrm{C})$, is given. Feasibility, reliability, and performance improvements on reconfigurabl transparent networks are expected to arise from the consolidated assessment of network management and control specifications as a more accurate evaluation of available $M \& C$ techniques. In the network layer, physical parameters aware algorithms are foreseen to pursue reliable network performance. In the physical layer, some new M\&C methods were developed and rating of the
\end{abstract}

A. Teixeira $(\varangle) \cdot$ L. Costa

Instituto de Telecomunicações, 3810-193 Aveiro, Portugal

e-mail: teixeira@ua.pt

L. Costa

e-mail:1costa@av.it.pt

G. Franzl

Institute of Broadband Communications, Vienna University of Technology, Favoritenstr. 9/388, 1040 Vienna, Austria e-mail: Gerald.Franzl@tuwien.ac.at

S. Azodolmolky $\cdot$ I. Tomkos

Athens Information Technology, 19002 Peania, Athens, Greece e-mail: azods@cmu.edu

I. Tomkos

e-mail: itom@ait.edu.gr

K. Vlachos

University of Patras, 26500 Rio, Greece

e-mail: kvlachos@ceid.upatras.gr

\section{S. Zsigmond $\cdot$ T. Cinkler}

Budapest University of Technology and Economics,

1117 Budapest, Hungary

e-mail: Zsigmond@tmit.bme.hu state-of-the-art reported in literature is given. Optical monitoring implementation and viability is discussed.

Keywords Dynamic networks - Optical performance monitoring · Impairment compensation - Network management and routing

\section{Introduction}

Reliability in dynamic, wavelength division multiplexed (WDM), photonic communication networks is becoming an

\footnotetext{
T. Cinkler

e-mail: cinkler@tmit.bme.hu

G. Tosi-Beleff

Instituto Superiore della Communicazioni e delle Tecnologiedell'Informazione, 00144 Rome, Italy e-mail:Giorgio.tosibeleffi@comunicazioni.i
}

P. Gravey · T. Loukina

Institut TELECOM, TELECOM Bretagne, Technopôle Brest-Iroise CS, 83818 - 29238 Brest Cedex 3, France

e-mail: Philippe.gravey@telecom-bretagne.eu

\section{J. A. Lázaro}

Universitat Politécnica de Catalunya, 08034 Barcelona, Spain e-mail: jose.lazaro@tsc.upc.edu

C. Vazquez · J. Montalvo

Universidad Carlos III de Madrid, 28911 Leganés, Madrid, Spain e-mail: cvazquez@ing.uc3m.es
J. Montalvo
e-mail: Julio.montalvo@uc3m.es
E. Le Rouzic
France Telecom, 2 av. P. Marzin, 22307 Lannion Cedex, France e-mail: esther.lerouzic@orange-ftgroup.com 
increasingly significant research topic. The combination of the ever-increasing demand for capacity, the generalization towards meshed network topologies, and widespread availability of dynamic optical switching, leads to severe constraints on quality of service (QoS) provisioning. These result from the difficult in maintaining a uniform and acceptable quality for any optical path across a transparent optical network comprising multiple fibe types, signal formats and data rates [1]. Furthermore, the quality of each optical path is often correlated with that of other optical paths due to optical impairments such as crosstalk, limited amplifie output power, or transients in optical amplifiers among others. In this scenario, newly emerging unforeseen demands often cannot be satisfie without modifying the network design, which is costly and time consuming.

A solution for the interoperability issues among network layers based on the introduction of dynamic M\&C capabilities must cope with the escalating complexity inherent to the deployment of more reliable transparent networks. The need to achieve higher performance levels and to enhance the network reconfiguratio capability \& autonomy is also spreading from core to metro and access networks [2].

In communication networks, routing generally performs the identificatio of a path (route), per connection request, between a source and a destination node, across the network. In optical networks, the particular wavelength(s) along the path should also be determined. The resulting problem is often designated as routing and wavelength assignment (RWA) problem in literature [3]. The existing RWA proposals can be classifie into two main categories: (a) considering the effects of impairments on network performance and (b) network design with impairment consideration. Although this is a widespread research topic, for transparent networks the incorporation of physical impairments in the RWA problem is still to be explored in full width. As such, a broader perspective over this problem, which surveys both, physical layer and management and control plane issues, is presented in this paper. The paper is organized as follows. Section 2 discusses impairment-aware RWA (IA-RWA) schemes as well as traffi grooming. An attempt to promote network performance optimization via impact analysis of physical impairments on quality of transmission (QoT) is made and a specificatio proposal for dynamic monitoring and compensation in terms of per-link and end-to-end control-loop characteristics given. Section 3 describes general requirements for successful implementation of monitoring methods in the physical layer, in order to establish a comprehensive comparison among existing $\mathrm{M} \& \mathrm{C}$ techniques from literature and some new developed described herein. The operator point of view of actual optical performance monitoring (OPM) requirements in current core networks is presented in Sect. 4. Section 5 concludes this paper.

\section{Network layer}

The reconfigurabl optical network offers the possibility to grow services between sites without advanced engineering or planning, and without disrupting services. The real innovation lies in the system engineering related to the reconfigurabl functions, addressing per-channel metrics and management, and fault isolation. The evolution of optical networks seems to tend towards a fully reconfigurabl network, where the control plane (CP) and management plane (MP) have new functions, intimately correlated with $\mathrm{M} \& \mathrm{C}$, such as determining the signal quality, tuning the wavelength frequency, setting dispersion compensation units and controlling channel powers.

\subsection{Management and routing}

\subsubsection{Introduction}

The RWA problem is an NP-complete problem with computational effort increasing exponentially with the problem size. Thus, a wide range of optimum approximation methods and heuristics have been proposed to solve various network optimization problems. Integer linear programming could be employed [4], but it requires heavy computational efforts. Other heuristic algorithms such as Tabu-search [5], simulated annealing [6], and genetic algorithms [7] with to some extent scalable computation effort have also been proposed. The latter, for instance, have been used to solve the plain single objective RWA problem [8], to optimize amplifie placement [9], as well as to optimize multicasting sessions [5].

Most IA-RWA approaches recently proposed still consider the QoT problem separately from the RWA problem [10,11]. A common strategy employed is to incorporate impairments into the cost function. However, a cost function for both linear and nonlinear impairments is still an open question. Different analytical models have been developed to describe reference links with or without compensation of fibe impairments [11, 12]. Only few studies, however, consider the simultaneous impact of chromatic dispersion (CD), polarization mode dispersion (PMD), amplifie spontaneous emission (ASE), and nonlinear phase shift [13]. Therefore, other more universal metrics have been used, including the average measured Q [14] or noise variance [12]. In any case, accurate $Q_{\text {path }}$ estimation is a heavy computational task, even in the static RWA problem, demanding offline calculation.

For an IA-RWA strategy to be actually implemented, one needs to consider also fundamental aspects like enabling Optical Impairment Monitoring (OIM) for indirect evaluation of signal quality, or enabling direct Optical Performance Monitoring (OPM) [15]. In 2004, ITU-T define a list of OPM parameters that might be used for impairment-aware 
RWA [16]. We consider the most important performance parameters to be: (a) residual chromatic dispersion (CD), (b) total EDFA input and output powers, (c) a channel's optical power budget, (d) optical signal-to-noise ratio (OSNR), and (e) Q-factor as an estimator of the overall optical performance. An effective OIM/OPM strategy shall also support the $\mathrm{CP}$ in performing lightpath establishment or re-routing functions, and can be accomplished through (a) a centralized approach, if all paths to be established within a domain are computed by a single and centralized network element (NE), e.g., a network management system (NMS), or path computation element (PCE) [17], or (b) a distributed approach, if a distributed and intelligent $\mathrm{CP}$, embedded in each NE, is responsible for both route computation and lightpath establishment.

\subsubsection{Multi-constraint distributed RWA applying service dependent vector-of-constraints and lattice algebra}

An RWA algorithm to consider any number and type of parameter individually has been presented in [18]. The presented scheme, entitled 'Distributed Wavelength-path Provisioning' (DWP), is proposed to maximally spread the computing effort, to improve accuracy of locally monitored parameters, and to avoid continuous distribution of all per link/node possibly relevant parameters. The basic idea is to sum-up parameters along potential paths on demand, distribute path messages selectively, and thereby exclude paths where service related end-to-end communication constraints are not met in the firs place (Step 2). The scheme consists of the 4 steps shown in Fig. 1.

As said before, any number and type of constraint can be considered in parallel, like QoT/BER \& delay \& reliability, as typically found in service level agreements (SLAs). As such, the fulfillmen of constraints is guaranteed as long as the parameters applied during path evaluation do not change. To cope with parameter changes the selection strategy (Step 3)

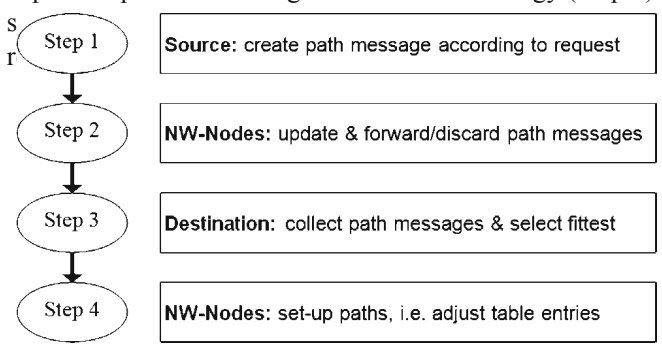

Fig. 1 CB-RWA using DWP algorithm to fin feasible all-optical endto-end paths parameters (e.g., OSNR, QoT). Monitoring of a path's endto-end performance can finall contribute to the control of SLA fulfillmen and trigger autonomous re-routing whenever the headroom diminishes below a constraint specifi threshold.

DWP's inherent strength is its individual per constraint operation that allows on-demand adoption to new constraints. However, it is not applicable for packet switching due to the effort introduced by the circulation of a great amount of path messages to fin candidate paths. Yet, some experts have recently proposed to control the network dynamics by limiting routing freedom. For instance, MPLS exactly performs that per-fl $\mathrm{w}$ (per ingress/egress pair). The routing underlying a label-switched path (LSP) typically does not change, and thus the effective effort introduced by findin feasible paths to transport a certain $\mathrm{fl} \mathrm{w}$ type with the demanded QoS inversely depends on the LSP life-time. Complex set-up procedures for long living LSPs thus actually introduce less effort if thereby frequent re-routing can be evaded.

\subsubsection{Cross layer impact of physical effects and traffic grooming in multilayer networks}

In general, for statically routed networks of practical size, the number of available wavelengths is lower by a few orders of magnitude than the number of connections to be established. The only solution here is to join some of the connections to fi into the available wavelength-paths. This is referred to as traffi grooming, which is possible to perform in the electric domain. It is assumed that there is no signal regeneration, and noise and signal distortion accumulate along lightpaths. Actually, 3R regeneration (re-amplification re-shaping, and re-timing) would be necessary to overcome these impairments. Although it has been demonstrated in laboratories, we consider that only electrical $3 \mathrm{R}$ regeneration is economically viable in current networks. To evade the physical limitations in the optical domain, optical/electrical/optical $(\mathrm{O} / \mathrm{E} / \mathrm{O})$ conversion needs to be (selectively) included to ensure the quality requirements. An algorithm has been proposed in [19] to investigate the effects of these $\mathrm{O} / \mathrm{E} / \mathrm{O}$ conversions on the RWA process. The algorithm can be split in two main parts: the routing part and the physical layer monitoring system (PLMS). The communication between these two parts is as follows. The routing algorithm chooses an optimal route between the source and destination node and, if the PLMS is switched on, it sends the description of the route to PLMS. The PLMS determines the signal quality and, if it is adequate, it sends a connection confirmatio message back to the routing part. If the signal quality is not adequate, the PLMS determines the most distant reachable node (MRN) along the path and sends this information back to the routing module. This establishes the connection between the source and the MRN and then chooses a route between the MRN 
and the destination node repeating the scheme. If MRN and source node coincide no possible connection exists and the connection is blocked.

In the proposed algorithm the impact of physical impairments on routing the demands in a grooming capable two-layer network is implicitly considered. The emphasis is on the mutual impact of grooming and physical impairments, i.e., application of the electronic time- and space-switching layer for signal regeneration and better joint resource utilization.

\subsection{Network performance optimization}

To achieve the per connection demanded maximum BER, bit errors caused by temporarily insufficien QoT, caused by the inertia of adjustments to changing traffi assignments, need to be considered. In case of M\&C at destination nodes this can be effectively done. However, any thereby forced adjustment must comply with all demands from other traffi fl ws sharing a resource along the path. For instance, adjusting the gain of all-optical amplifier being part of links carrying many $\mathrm{fl}$ ws based on all the individual per lightpath (end-to-end) monitored parameters is very complex. Instead, for such, per-link (fibe section) monitored parameters that influenc all carried fl ws similarly should be used.

The exact calculation of parameters for M\&C to achieve optimal performance poses a fundamental mathematical problem. This is illustrated in Fig. 2 where an abstract impairment is considered. Demand on received QoT is -10 to -3 , degradation per link is -5 , input QoT is +3 , and the compensation can be adjusted between -3 and +3 , i.e., degradation cannot be completely compensated but deliberately worsened $a_{i j}=[-8 . .-2]$, as typical for physical impairments.

To solve the simple dimensioning problem depicted in Fig. 2, we can set up the according equation system:

$$
\begin{aligned}
& P\left(\text { Dest }_{1}\right)=3-a_{12}-a_{23}-a_{34} \\
& P\left(\text { Dest }_{2}\right)=3-a_{51}-a_{12} \\
& P\left(\text { Dest }_{3}\right)=3-a_{34}-a_{45}-a_{51}
\end{aligned}
$$

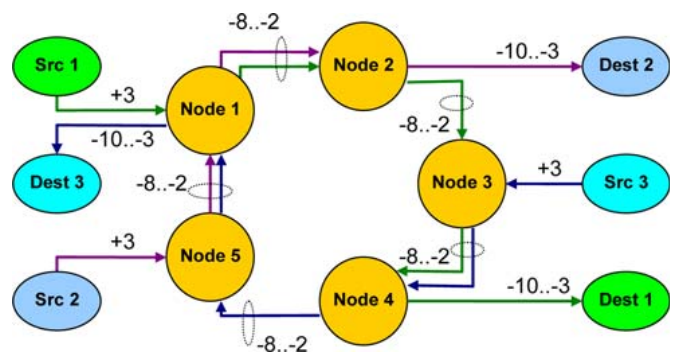

Fig. 2 NP hard problem of interdependent adjustments
We have three equations for fi e variables, a multi-dimensional continuum of feasible solutions, and thus might assume that an optimum solution providing fair connection quality distribution among all three connections could be found. However, there is a cyclic dependence and parameters are bound to certain intervals adding additional equations. Solving the equation system for feasible real numbers yields not the best solution, i.e., degradation of -8 while in one by one mode we get far better results $[-3 . .-5]$. We can state that a solution providing equal quality per connection, if it exists, for the example scenario does not yield an optimum. Further, as cycles alike the discussed likely exist in every meshed topology, we derive that, in general, solutions that grant equal quality per connection are suboptimal if impairments cannot be compensated $100 \%$ in the firs place.

A global optimization approach based on complex and time consuming calculations (e.g., integer linear programming), which relies on a network-wide knowledge of every single fl w and resource parameter, appears inadequate for dynamic environments and is unsuited for real-time controlloops. Non-real-time operation allowing off-line calculations would demand synchronized, and, more restrictive, considerably delayed changes in traffi assignments, which is a clear contradiction to dynamic traffi management as featured in optical packet switched (OPS) and optical burst switched (OBS) architectures. We should consequently drop the optimum performance requirement and demand stable performance with least effort, i.e., minimal added cost. Therefore, parameters which can be efficientl stabilized per link shall be managed by per link control-loops, all other per lightpath. This clearly does not grant global optimization. Nonetheless, stable and reliable impairment management is likely more important than squeezing out the least quantum of optical span potentially possible.

\subsection{Specification for dynamic monitoring and compensation}

\subsubsection{Introduction}

The heavy dependence of the feasibility of optical spans on the dynamic performance of the physical components and the quality demands of special lucrative services justify the use of performance monitoring for dynamic lightpath management purposes. Performance stability of several components is to some extent dependent on the traffi load and that demands efficien control to be deployed in dynamic environments.

Traditionally the stability is gained by controlling the environment, e.g., adding dummy channels to keep optical power constant when not all wavelengths are in use. Today more dynamic approaches are demanded, since traditional ones are designed and optimized for the entirely opaque, $\mathrm{O} / \mathrm{E} / \mathrm{O}-$ based network architectures. In dynamically switched all-optical 
networks the stabilization of physical parameters should be the prime target. When we look at next generation optical networking paradigms, e.g., OBS and OPS, we must solve the problem of keeping the performance of physical components constant, i.e., independent of dynamically changing traffi assignment, to enable their future deployment.

\subsubsection{Impact of physical impairments compensation on QoS respectively SLA fulfilment}

Customers demand QoS derived from SLAs, which typically consist of statistical metrics, i.e., average and/or maximum (maximum typically a highly probable bound, not an absolute value), on BER, loss-rate, and latency. If BER is met, loss-rate and latency are not related to physical impairments, i.e., loss or repetitions of content are not caused by insufficien BER. Thus, we need to consider BER as the only service requirement dependent on the control of physical impairments.

BER is directly related to QoT, although, the relation depends on modulation format and receiver technology. We can assume that the average values are met by design, respectively, by the applied RWA scheme. The contribution of the considered physical impairments to QoT degradation is expressed in (1).

$\mathrm{QoT}_{[d B]}=Q_{\mathrm{OSNR}}-Q_{\mathrm{GVD}}-Q_{\mathrm{DGD}}-Q_{\mathrm{FWM}}-\cdots$

where $Q_{\text {OSNR }}=P_{\text {signal }} / P_{\text {noise }}$ reflect the eye-opening at the receiver after consideration of amplifie spontaneous emission (ASE) noise. The other are eye-closures caused by other linear and nonlinear, potentially signal or technology dependent, effects. For stabilization we need to consider the dependence of the contributing components on changes of traffi load (sensitivity), their relative impact on QoT (impact), and how fast they possibly could be compensated (speed), alike the assumptions shown in Table 1.

\subsubsection{An attempt to specify control-loop characteristics}

The specification for impairment compensation can be stated individually for the per-link and the per-lightpath controlloops (Tables 2 and 3 ).

To which extent these specification contribute to SLA fulfillmen depends on the number of hops $\mathrm{n}$ with adjustments originated temporarily increased BER (BER transient):

Table 1 Assumed parameters contributing to QoT

\begin{tabular}{llll}
\hline Parameter & Sensitivity & Impact & Speed \\
\hline QOSNR & Low & Linear & Moderate \\
QGVD & Low & Exponential [20] & Slow \\
QDGD & Moderate & Exponential [21] & Fast [22] \\
QFWM & High & Nonlinear & N/A \\
\hline
\end{tabular}

Table 2 Exemplary specification for per-link control loops

\begin{tabular}{llll}
\hline $\begin{array}{l}\text { Parameter } \\
\text { name }\end{array}$ & $\begin{array}{l}\text { Stabilization } \\
\text { target }\end{array}$ & $\begin{array}{l}\text { Monitoring } \\
\text { speed }\end{array}$ & $\begin{array}{l}\text { Adjustment } \\
\text { speed }\end{array}$ \\
\hline $\begin{array}{l}\text { Inserted light- } \\
\text { power (fiber }\end{array}$ & $\pm \mathrm{x} \mathrm{dBm}$ & Fast (ns) & Moderate (ms) \\
$\begin{array}{l}\text { Chromatic } \\
\text { dispersion }\end{array}$ & $\pm \mathrm{x} \mathrm{ps}$ & Moderate (ms) & Fast (ns) \\
\hline
\end{tabular}

Table 3 Exemplary specification for per-lightpath control loops

\begin{tabular}{llll}
\hline $\begin{array}{l}\text { Parameter } \\
\text { name }\end{array}$ & $\begin{array}{l}\text { Stabilization } \\
\text { target }\end{array}$ & $\begin{array}{l}\text { Monitoring } \\
\text { speed }\end{array}$ & $\begin{array}{l}\text { Adjustment } \\
\text { speed }\end{array}$ \\
\hline OSNR & $\mathrm{X} \mathrm{dB}$ & Slow (s) & $\begin{array}{l}\text { Moderate (ms) } \\
\text { Center wavelength }\end{array}$ \\
$\begin{array}{l} \pm \mathrm{x} \mathrm{nm} \\
\text { PMD }\end{array}$ & Fast (ns) & Slow (s) \\
\hline
\end{tabular}

$$
\begin{aligned}
& B E R_{\text {transient }}\left(\text { link }_{i}\right) \\
& \quad=p_{\text {adj }}(i) E\left[\text { bit error } \mid Q o T(t)<Q o T_{\text {target }}\right] \\
& B E R_{\text {transient }}<\sum_{i=0}^{n} B E R_{\text {transient }}\left(\text { link }_{i}\right) \\
& \quad+p_{\text {adj }}(l p) E\left[\text { bit error } \mid Q o T(t)<Q o T_{\text {target }}\right]
\end{aligned}
$$

where $p_{\text {adj }}(\mathrm{i})$ is the probability for adjustments on the $i$-th link in the path, $p_{\text {adj }}(\mathrm{lp})$ the probability for per lightpath adjustments, and E[bit error $\left.\mid \mathrm{QoT}(\mathrm{t})<\mathrm{QoT}_{\text {target }}\right]$ is the likelihood for bit-errors in case current QoT is below target QoT, i.e., current BER is above that for stable operation.

To get an upper bound let us assume a worst case: No end-to-end headroom and complete detector malfunction for QoT $(1 \mathrm{p})<\mathrm{QoT}_{\text {target }}$, i.e., E[bit error $\left.\mid \mathrm{QoT}(\mathrm{t})<\mathrm{QoT}_{\text {target }}\right]$ $=0.5$. If we additionally simplify and assume the probability for adjustments to be equal for all links and lightpaths, Eq. 2 reduces to:

BER $_{\text {transient }}<\frac{(n+1)}{2} p_{\text {adj }}$

To minimize the transient impact we need to minimize $p_{\text {adj }}$. As $p_{\text {adj }}$ is calculated as required number of adjustments per time-unit multiplied by time-units these adjustments cause QoT $(\mathrm{t})<\mathrm{QoT}_{\text {target }}$, only the latter can be addressed by design of compensation mechanisms. The common problem of control-loop design, reaction speed versus stabilization time, then arises along with the acknowledgement of cascaded, potentially interdependent, control-loops as the compensation mechanism performance specificatio parameters.

A simple approach to solve the problem would be to enforce asymptotic control-loop behavior. However, if there is some headroom for sufficien detection, slight overshot might be acceptable and faster loop operation and reduced number of bit-errors per adjustment would be possible. To solve that we again need to solve a problem as that depicted 
in Fig. 2 to cope with the cascades and interdependencies, which now can be done off-line using the methods mentioned earlier, since control-loop performance characteristics are independent of instantaneous traffi load. Nevertheless, the results will depend heavily on actual traffi statistics and network topology.

We conclude that the control-loop performance targets for the deployment of physical impairments compensation mechanisms in arbitrarily meshed transparent networks with dynamic traffi assignment cannot be specifie independent of traffi characteristic (holding time distribution), traffi matrix (likelihood of fl ws per node pair), and network topology (average and maximum path length). For network architectures comprising restriction to a certain topology and stable traffi distribution the specs need to be individually derived.

Only if stabilization is reached within a fraction of a single optical pulse, or if adjustments have per se no effect on QoT, traffi assignment dynamics independent QoT could be achieved $\left(\mathrm{BER}_{\text {transient }}=0\right)$. Assuming that out of reach, we conclude that the demand on stabilization speed is directly related to traffi assignment dynamics. To achieve the same BER as for today's non-dynamic optical connections, the QoT needs to provide sufficien extra head-room. The slower the stabilization, the more hops, the more dynamic traffi changes cause adjustments, the more QoT head-room is required and that needs to be granted by constraint-based RWA.

A switched layer 0 (the transparent analogous physical layer) lacking transparent $3 \mathrm{R}$ regeneration with every hop can in general not grant constant QoT and thus shall not be responsible for electrical-to-electrical BER liability, even if that demands renunciation from common attitudes.

\section{Physical layer}

There is an increasing interest in transferring some monitoring capabilities, which were exclusively managed by SDH/ SONET [23], to the physical layer in order to enable fully reconfigurabl and transparent optical networks, with improved reliability and fl xibility. Even in the context of access networks, where advanced monitoring capabilities are not implicitly considered at first they eventually become crucial to perform packet synchronization, power equalization [24], or link fault detection and identificatio in Giga-capable networks, contributing for system resilience, as well as for increased reach and overall end user number served.

OPM started by focusing attention on simple channel parameters, like wavelength and optical power, but rapidly advanced to more complex and sophisticated solutions, such as simultaneous and independent monitoring of different physical impairments [1]. The lack of standardization and low maturity level of monitoring methods and systems is still significant. For these reasons, research work on this topic appears in literature in a large extent. As such, the choice of more adequate $\mathrm{M} \& \mathrm{C}$ techniques is a complex task. Moreover, there is no perfect method capable of meeting the entire requirements imposed by transparent networks [23]. To cope with this, we have produced a collection of state-ofthe-art monitoring methods and developed rating criteria to enable straightforward comparison between them. Investigation, improvement, and validation of some new impairmentspecifi monitoring techniques are also presented.

\subsection{Monitoring techniques evaluation}

One would agree that technological evolution and commercial deployment are essentially dependent on one critical lim-

Table 4 OSNR monitoring techniques

\begin{tabular}{|c|c|c|c|}
\hline Criteria & $\begin{array}{l}\text { Orthogonal } \\
\text { polarization } \\
\text { heterodyne } \\
\text { mixing [25] }\end{array}$ & $\begin{array}{l}\text { Nonlinear } \\
\text { loop mirror } \\
{[26]}\end{array}$ & $\begin{array}{l}\text { Hi-birefringent } \\
\text { loop mirror [27] }\end{array}$ \\
\hline Type $^{\mathrm{a}}$ & $\mathrm{O}$ & $\mathrm{O}$ & $\mathrm{O}$ \\
\hline $\begin{array}{l}\text { Accuracy/sensi- } \\
\text { tivity }\end{array}$ & Moderate & $*$ & Moderate \\
\hline Dynamic range & Low & High & Moderate \\
\hline $\begin{array}{l}\text { Other } \\
\text { impairments } \\
\text { insensitivity }^{b}\end{array}$ & Moderate & Low & Moderate \\
\hline $\begin{array}{l}\text { Modulation } \\
\text { format } \\
\text { transparency }\end{array}$ & Yes & Yes & Yes \\
\hline $\begin{array}{l}\text { Bit rate } \\
\text { transparency }\end{array}$ & Yes & Yes & Yes \\
\hline $\begin{array}{l}\text { Transmitter } \\
\text { modificatio }\end{array}$ & No & No & No \\
\hline Multi-channel & No & No & No \\
\hline Multi-parameter & No & No & Yes \\
\hline $\begin{array}{l}\text { Implementation } \\
\text { complexity }^{\mathrm{c}}\end{array}$ & Simple & Suitable & Simple \\
\hline $\begin{array}{l}\text { Technological } \\
\text { requirements }\end{array}$ & Good & Suitable & Good \\
\hline $\begin{array}{l}\text { Acquisition } \\
\text { time }\end{array}$ & Fast & Moderate & Fast \\
\hline $\operatorname{Cost}^{\mathrm{f}}$ & Low & Low & Low \\
\hline
\end{tabular}

* There is not sufficien information in literature

a 'O'means optical; 'E' means electrical; 'O/E' means optical/electrical

b Insensitiveness of the monitored physical quantity to other impairments and robustness to environmental parameters (e.g. temperature)

${ }^{\mathrm{c}}$ Complex when stabilization via filtering carrier dithering, or phase-locked loops are required, and/or the amount of electronic or optical pre- and post-processing involved is high

${ }^{d}$ Low power consumption, compactness, non-intrusiveness, and scalability

e Considered fast if less than $1 \mathrm{~ms}$

${ }^{f}$ A low cost-solution is a comprehensive concept, which includes: (i) multi-channel ability, (ii) multi-parameter ability, (iii) simplicity of implementation, (iv) good agreement with technological requirements, and (v) low overall cost of the electrical/optical components which constitute the device 
Table 5 GVD Monitoring techniques

\begin{tabular}{|c|c|c|c|}
\hline Criteria & $\begin{array}{l}\text { RF pilot } \\
\text { tones [28] }\end{array}$ & $\begin{array}{l}\text { Polarization Asynchronous } \\
\text { scrambling chirp [30] } \\
{[29]}\end{array}$ & $\begin{array}{l}\text { TPA with } \\
\text { semiconduc- } \\
\text { tor micro- } \\
\text { cavity [31] }\end{array}$ \\
\hline
\end{tabular}

\begin{tabular}{|c|c|c|c|c|}
\hline Type $^{\mathrm{a}}$ & $\mathrm{O} / \mathrm{E}$ & $\mathrm{O} / \mathrm{E}$ & $\mathrm{O}$ & $\mathrm{O}$ \\
\hline $\begin{array}{l}\text { Accuracy/sensi- } \\
\text { tivity }\end{array}$ & High & High & High & $*$ \\
\hline Dynamic range & Moderate & Moderate & Moderate & High \\
\hline $\begin{array}{l}\text { Other } \\
\text { impairments } \\
\text { insensitivity }^{\mathrm{b}}\end{array}$ & Moderate & Moderate & Low & Low \\
\hline $\begin{array}{l}\text { Modulation } \\
\text { format } \\
\text { transparency }\end{array}$ & Yes & Yes & Yes & Yes \\
\hline $\begin{array}{l}\text { Bit rate } \\
\text { transparency }\end{array}$ & Yes & Yes & Yes & Yes \\
\hline $\begin{array}{l}\text { Transmitter } \\
\text { modificatio }\end{array}$ & Yes & No & No & No \\
\hline Multi-channel & No & No & No & Yes \\
\hline Multi-parameter & No & Yes & No & No \\
\hline $\begin{array}{l}\text { Implementation } \\
\text { complexity }\end{array}$ & Suitable & Simple & Simple & Suitable \\
\hline $\begin{array}{l}\text { Technological } \\
\text { requirements }\end{array}$ & Good & Good & Good & Good \\
\hline $\begin{array}{l}\text { Acquisition } \\
\text { time }\end{array}$ & Moderate & Fast & Fast & Fast \\
\hline $\operatorname{Cost}^{\mathrm{f}}$ & Moderate & Low & Low & Low \\
\hline
\end{tabular}

Note: See Table 4 for footnote details

Table 6 PMD Monitoring techniques

\begin{tabular}{|c|c|c|c|}
\hline Criteria & $\begin{array}{l}\text { Polarization- } \\
\text { based } \\
\text { interferometric } \\
\text { filte [32] }\end{array}$ & $\begin{array}{l}\text { Degree of } \\
\text { polarization } \\
{[33]}\end{array}$ & $\begin{array}{l}\text { Partial bit } \\
\text { delay } \\
\text { MZI [34] }\end{array}$ \\
\hline Type $^{\mathrm{a}}$ & $\mathrm{E}$ & $\mathrm{O}$ & $\mathrm{O}$ \\
\hline $\begin{array}{l}\text { Accuracy/sensi- } \\
\text { tivity }\end{array}$ & High & $*$ & $*$ \\
\hline Dynamic range & High & Moderate & High \\
\hline $\begin{array}{l}\text { Other } \\
\text { impairments } \\
\text { insensitivity }\end{array}$ & Low & Moderate & Good \\
\hline $\begin{array}{l}\text { Modulation } \\
\text { format } \\
\text { transparency }\end{array}$ & Yes & No & Yes \\
\hline $\begin{array}{l}\text { Bit rate } \\
\text { transparency }\end{array}$ & Yes & Yes & No \\
\hline $\begin{array}{l}\text { Transmitter } \\
\text { modificatio }\end{array}$ & No & No & No \\
\hline Multi-channel & No & No & No \\
\hline Multi-parameter & No & No & Yes \\
\hline $\begin{array}{l}\text { Implementation } \\
\text { complexity }^{\mathrm{c}}\end{array}$ & Complex & Simple & Simple \\
\hline $\begin{array}{l}\text { Technological } \\
\text { requirements }\end{array}$ & Good & Suitable & Suitable \\
\hline $\begin{array}{l}\text { Acquisition } \\
\text { time }^{\mathrm{e}}\end{array}$ & Moderate & Fast & Moderate \\
\hline $\operatorname{Cost}^{\mathrm{f}}$ & Expensive & Low & Low \\
\hline
\end{tabular}

Note: See Table 4 for footnote details iting factor: cost. However, it would not be a wise decision to choose an OPM technology or method based on just a single criterion. Thus, general criteria were derived from the considered three main factors: cost, robustness, and scalability. To simplify the task the methods were divided according to the actual impairment to be monitored. Here, only OSNR, group velocity dispersion (GVD) and polarization mode dispersion (PMD) monitoring methods are contemplated. Some of the techniques which fi best the designated criteria are shown in Tables 4,5 and 6 .

Some of the information needed to fil the table according to the criteria does not exist in the consulted literature. In that case, we report our own assumptions, at the exception of the quantitative criteria. These comparison criteria can also be used for rating of compensation techniques with minor modifications

\subsection{Advanced optical performance monitoring and compensation}

\subsubsection{Multi-channel OPM based on free-space optics}

Free space optics can be applied to conceive optical monitoring devices. The use of only passive optical components in an OPM device enables fast spectrum acquisition times, with lower cost. The optical design of our device, based on a diffraction grating and a photo-detector array, involves a trade-off between the image spot dimension, the array pitch and the multiplex spectral bandwidth. Proper operation with $50 \mathrm{GHz}$ spaced DWDM channels can be enabled by two ways: either by using (a) a very high dispersion diffraction grating and a photodiode array with more than 1000 detectors or by using (b) a moderate resolution optical system associated with sophisticated channel reconstruction protocol [35]. The second option is more cost-effective, although it implies partial superposition of adjacent channels.

An OPM prototype with a low PDL $900 \mathrm{~mm}^{-1}$ reflectio relief grating, and a 512 pixels $\mathrm{InGaAs}$ array with $25 \mu \mathrm{m}$ pitch integrated in commercial linear camera was experimentally evaluated. Several optical configuration were simulated using ZEMAX $^{\mathrm{TM}}$ software in order to fin the best, which corresponds to a couple of lenses with 30 and $250 \mathrm{~mm}$ focal lengths and an incident angle on the grating of $53^{\circ}$. A specifi control software featuring the generation of a table of monitored parameters (power level, wavelength, ITU channel number, OSNR), the definition of alarm generation criteria, and the display of these alarms, was developed.

The channel profil reconstruction routine has to deal with two main problems: (i) the choice of a suitable reference shape for each channel, in order to provide its power and optical carrier frequency accurately, and (ii) the influenc of closed channels. With an individual channel reconstruction method the $-3 \mathrm{~dB}$ transfer function width is about $25 \mathrm{GHz}$, 
hich is much wider than a standard (NRZ or RZ) $10 \mathrm{Gbit} / \mathrm{s}$ modulated spectrum. Therefore, a simple Gaussian approximation of the spectral shape is valid for $10 \mathrm{Gbit} / \mathrm{s}$. For 40 $\mathrm{Gbit} / \mathrm{s}$, this may not be valid, and different reference shapes representative of the various modulation formats may need to be used. The tests reported here were performed under the Gaussian approximation.

We then developed a collective profil reconstruction method which fit data with a sum of Gaussian functions to increase reconstruction accuracy. The width of a sliding window is locally adjusted, in order to optimize the trade-off between reconstruction accuracy and computing time. We then compared the accuracy of the individual and collective reconstruction methods in presence of groups of $50 \mathrm{GHz}-$ spaced non-modulated channels, for which the optical power of all odd-number channels was varied. For the individual profil reconstruction, the accuracy decreases with increas- ing inter-channel power difference and for low-power channels, the maximum power deviation is more than $0.5 \mathrm{~dB}$. This does not occur for the collective profil reconstruction, where power accuracy remains better than $0.3 \mathrm{~dB}$ (see Fig. 3). We also evaluated our prototype in presence of up to 40 multiplexed channels spaced at 100 or $50 \mathrm{GHz}$, with NRZ format at $40 \mathrm{Gbit} / \mathrm{s}$. Both individual and collective methods yield a correct reconstruction, which is shown in Fig. 4, for a group of four $50 \mathrm{GHz}$-spaced channels.

Finally, we tested the OPM prototype with forty $100-\mathrm{GHz}$ spaced $40 \mathrm{Gbit} / \mathrm{s}$ modulated channels using either CSRZ or RZ33\% modulation formats. For these formats, one channel presents two $40 \mathrm{GHz}$ separated equal peaks (CSRZ format) or one central peak with two secondary lobs (RZ 33\% format), which are always detected and reconstructed as separated channels by our device. It is clear that for these advanced modulation formats, like CSRZ, a specifi non-Gaussian
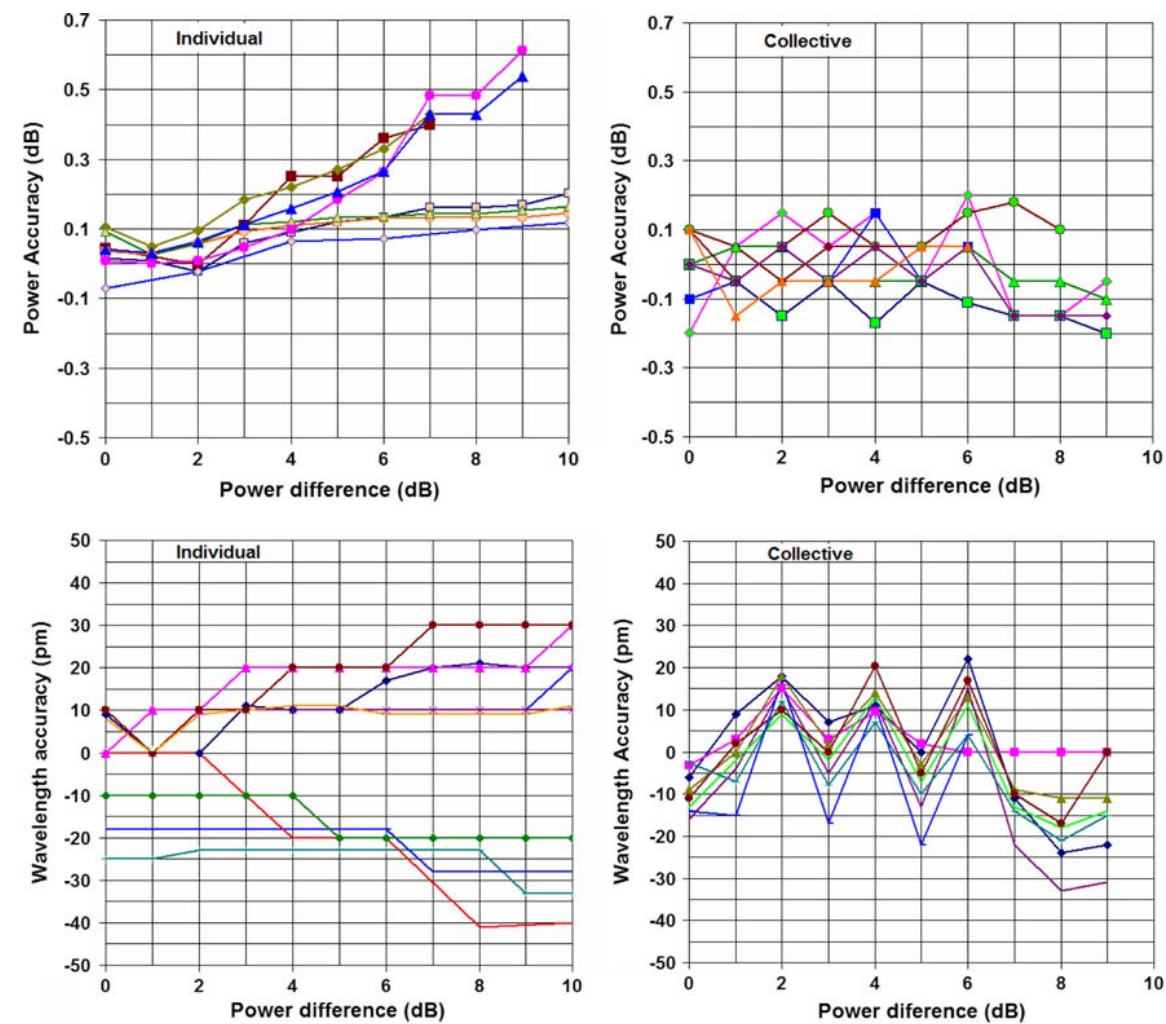

Fig. 3 Power (top) and wavelength (down) accuracy versus power difference between neighboring $50 \mathrm{GHz}$-spaced channels for individual (left) and collective (right) reconstruction methods 


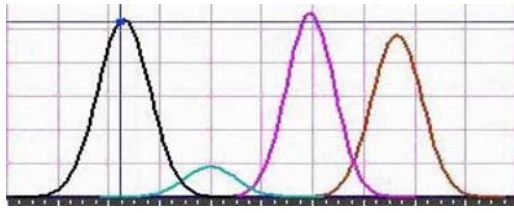

Fig. 4 Individual (left) and collective (right) reconstructions of four $50-\mathrm{GHz}$ spaced NRZ $40 \mathrm{Gbit} / \mathrm{s}$ channels with $7 \mathrm{~dB}$ power difference between neighboring channels; for collective reconstruction, the red

reconstruction model is required. Work is in progress to test this new feature.

\subsubsection{Dynamic and remote OTDR monitoring}

Metro and extended Access Networks are showing a tendency towards convergence due to the urge of deploying transparent WDM optical networks. A fully passive and transparent Metro-Access network, SARDANA, has been proposed and investigated [36].

It has shown to be able to provide broadband access up to $10 \mathrm{Gbit} / \mathrm{s}$ to more than 100 users covering more than $100 \mathrm{~km}$ [37]. Figure 5 shows a possible scenario where several MetroAccess networks are connected to a possible Regional network. In this case, one or more Central Office (CO) are connected to the nodes of the Regional network, where M\&C modules can be distributed. We concentrate in this section in describing a method and the developed equipment required for monitoring transparent passive Metro-Access networks.

Since the proposed Metro-Access network is fully passive, electronic equipment has to be concentrated at $\mathrm{CO}$ or at Optical Network User equipment (ONU). Remote monitoring is preferred at the $\mathrm{CO}$ since it is a more $\mathrm{fl}$ xible approach for operators, not requiring any kind of ONU equipment upgrade or installation costs.

On one hand, each section of the Metro-Access network with tree topology is working at a fi ed wavelength [36]. Thus, it was necessary to implement a tunable OTDR for monitoring the different sections of the network. This was done by using a Grating-Coupled Sampled Reflecto tunable laser (GCSR), as shown in Fig. 6 [38].

Fast tuning of the output signal from the GCSR of only $145 \mathrm{GHz}$ allows generating well formed pulses, with an extinction of $>35 \mathrm{~dB}$, as shown in Fig. 7 .

On the other hand, the Metro-Access network can be deployed using next generation single fibe reflect ve ONUs, with the disadvantage of having to deal with Rayleigh Backscattering [39]. In order to minimize this impairment, a double fibe ring is implemented. As such, the experimental OTDR trace shown in Fig. 8 has to be interpreted. After analysis of the experimental data, adequate performance of the diverse elements of the Remote Node (RN) can be remotely

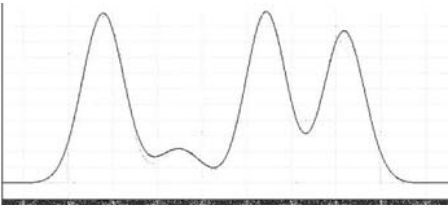

curve represents the signal generated by the photodiode array, the green one corresponds to the interpolation of rough data, and the white line is the reconstructed channel profil

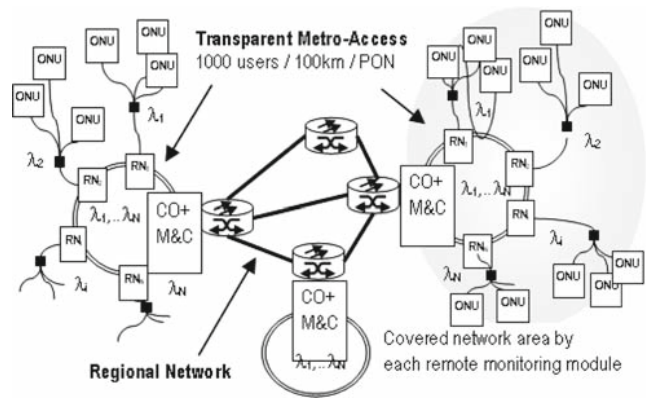

Fig. 5 Scenario for application of remote/distributed Monitoring and Compensation modules to extended transparent Metro-Access networks

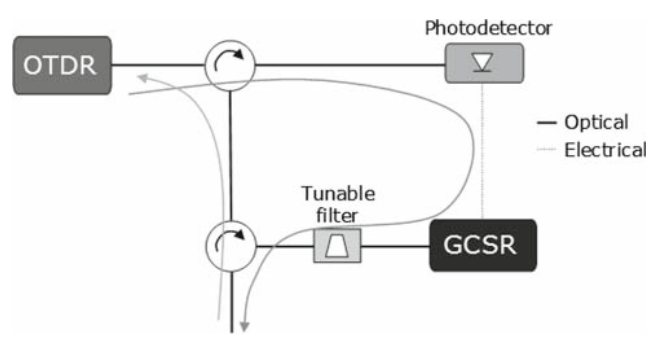

Fig. 6 Implementation of the tunable OTDR using a GCSR laser and an optical filte

checked. They are, for the downstream path: $-1.5 \mathrm{~dB}$ (filte loss), $-3.1 \mathrm{~dB}(50 / 50$ power splitter), $+25 \mathrm{~dB}$ (EDFA gain), $-0.4 \mathrm{~dB}$ (circulator), and, for the upstream path: $-0.4 \mathrm{~dB}$ (circulator), $+18 \mathrm{~dB}$ (EDFA gain), $-3.1 \mathrm{~dB}$ (power splitter), and $-1.8 \mathrm{~dB}$ (filte loss), in agreement with independent characterization of each component.

Following the described procedure, each section of the Metro-Access network can be analyzed by tuning the remote OTDR to each one of the $\lambda_{1}$ to $\lambda_{N}$ wavelengths and the WDM ring by selecting a non-assigned wavelength. Finally, the Raman amplificatio gain can be characterized and monitored, as well as the consumption of the remote pumping provided by the $\mathrm{CO}$ for feeding the EDFAs at the RNs [36]. 


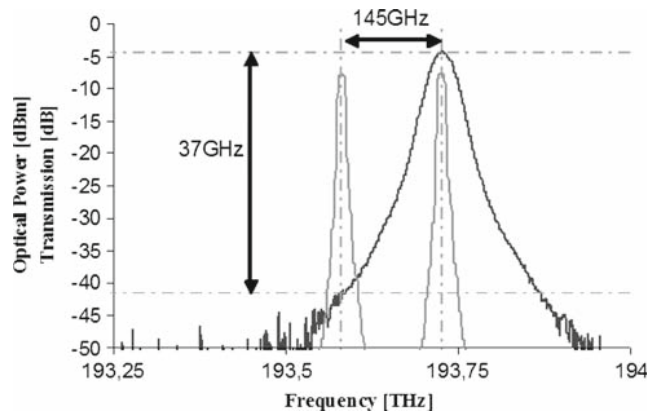

Fig. 7 Spectrum of the laser emission and transmission function of the tunable filte . Center wavelength: $1547.50 \mathrm{~nm}$
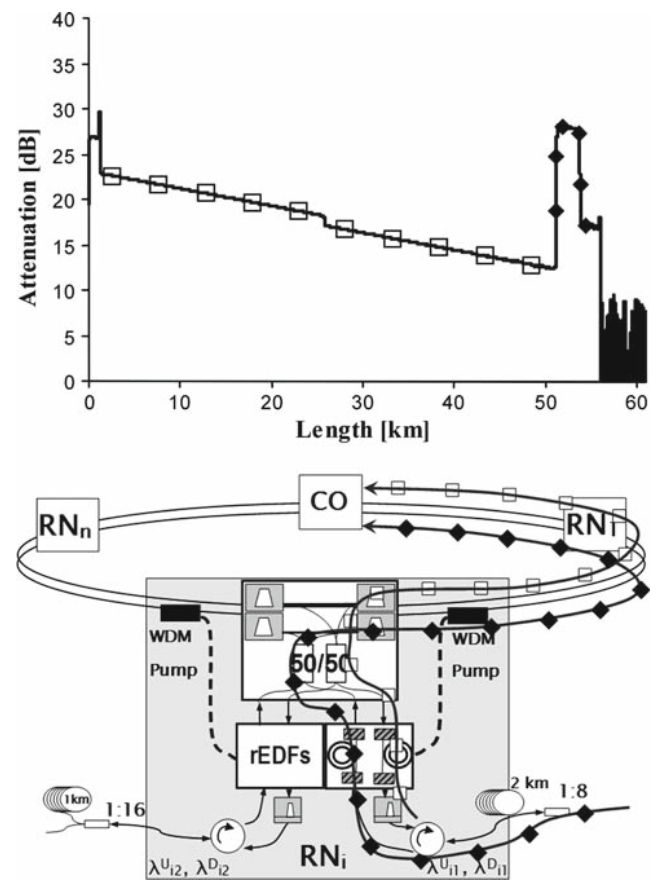

Fig. 8 OTDR measurement and corresponding sections of the network monitored by the proposed technique

The described remote monitoring method provides a powerful tool for the implementation of transparent networks.

\subsubsection{Tunable CD compensation with a Sagnac loop in ring resonators}

Fiber-optic interferometers, such as the Fabry-Perot (FP) and the ring resonator (RR), have long been considered possible

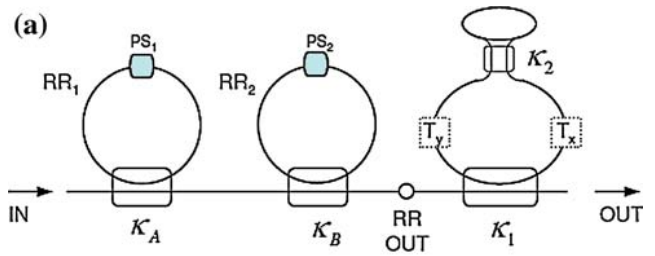

(b) Dispersion [1e3ps/nm]

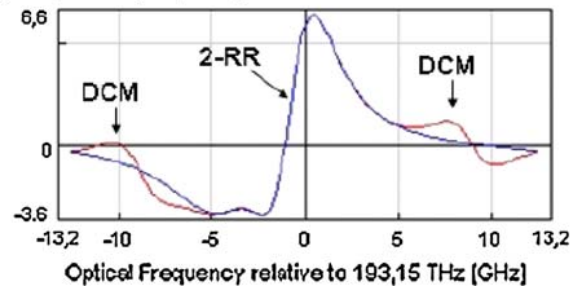

Fig. 9 a Proposed DCM schematic for chromatic dispersion compensation cascading two RR and a RR-SG configuration PS: Phaseshifter. b Quadratic dispersion of a 2-RR + RR-SG filte with $\mathrm{FSR}=25 \mathrm{GHz}$ for chromatic dispersion compensation. RR-SG parameters: $k_{1}=0.3, k_{2}=0.8, g_{1}=g_{2}=0.925$

CD compensating filter for high bit rate digital transmission systems [40]. To achieve flat-respons in a proper bandwidth, higher order filte should be developed. Recently, a RR with SG loop filte (RR-SG), as the one shown in third block of Fig. 9a, has been reported as a second order tunable optical filte with ultra-narrow-bandwidth for use in DWDM systems [41] or as part of a novel filte design technique [42]. It can also be used for designing tunable dispersion compensation modules (DCMs) by changing the value of the coupling factor $k$, and to achieve higher order designs in combination with other FIR filters

In Fig. 9a, a specifi example of a DCM based on a compound filte made of a 2-RR + RR-SG is presented. The quadratic dispersion of this DCM is shown in Fig. 9b. The dispersion compensating bandwidth of the left sidelobe of this DCM is the double of the DCM based only on the 2-RR fil ter, for a value of quadratic dispersion around $-3100 \mathrm{ps} / \mathrm{nm}$, which is in principle capable of compensating the chromatic dispersion of around $194 \mathrm{~km}$ of SMF. Figure $9 \mathrm{~b}$ also shows that the central frequency of the DCM equals the center of the left-sidelobe with negative dispersion and it emits $0 \mathrm{dBm}$ of average output power.

The performance of RR-SG-based filter in an optical digital transmission system operating at high bit rates was tested. A simplifie model of a fibe link has been built using the VPI PhotonicsTM v. 7.01 software simulation engine.

Figure 10 shows the transmitter, consisting of a $10 \mathrm{MHz}$ linewidth distributed-feedback laser diode (DFB-LD), which 


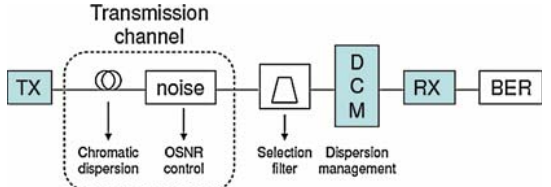

Fig. 10 Simplifie model of a digital transmission link with chromatic dispersion and white noise from amplifier

is externally modulated by a pseudo-random NRZ signal at $5 \mathrm{Gbit} / \mathrm{s}$. The second block is a simplifie transmission channel, which consists of a CD generator and a white noise generator. The dispersion generator is just a single-mode fibe model without attenuation, with a dispersion of $16 \mathrm{ps} / \mathrm{nm}+\mathrm{km}$ and a slope of $0.08 \mathrm{ps} / \mathrm{nm}^{2}+\mathrm{km}$ at the central frequency of the simulations. Simulation results demonstrate that, for a fi ed OSNR of $13 \mathrm{~dB}$ and for a fibe length between $150 \mathrm{~km}$ and $300 \mathrm{~km}$, the optical data link is not feasible without dispersion management, which can be solved by using the proposed DCM.

\subsection{Signaling in optical networks}

Provisioning in a network is controlled through the MP. A similar function to provisioning using automatic configura tion refers to signaling, which is a feature of the $\mathrm{CP}$. In a PON, the adoption of EDFAs in the Central Offic (CO), where the Optical Line Terminals (OLTs) are placed, can be used for signaling and monitoring purposes.

The experimental setup to evaluate the performance of this signaling technique for PONs is depicted in Fig. 11. An External Cavity Laser (ECL), tuned at $1,537 \mathrm{~nm}$ is exter- nally modulated at $10 \mathrm{Gbit} / \mathrm{s}$ rate by a 231-1 PRBS signal. The $980 \mathrm{~nm}$ diode pump (SDL0 2596) is directly modulated up to $60 \mathrm{Mb} / \mathrm{s}$ by a 215-1 PRBS signal with a modulation depth of around $50 \%$. A T-bias $(100 \mathrm{kHz}-1 \mathrm{GHz})$, not shown in figure provides biasing and signaling modulation. The bias current, at the laser working point, is $80 \mathrm{~mA}$ for an optical output power of $90 \mathrm{~mW}$. In this condition the EDFA gain is $20 \mathrm{~dB}$ and its output power is $14 \mathrm{dBm}$ at ECL wavelength. Both modulated signals are sent to a $2 \mathrm{~km}$ single mode fibe coil. This length has been demonstrated to be in Italy the average distance between the $\mathrm{CO}$ and the end user. The optical attenuators simulate the power reduction which is mainly caused by the splitter in a PON.

Figure $12 \mathrm{~b}$ shows the BER curves, for the $10 \mathrm{Gbit} / \mathrm{s}$ signal, which have been taken in absence and in presence of the $50 \mathrm{Mb} / \mathrm{s}$ pump modulating signal. When the signaling at $50 \mathrm{Mb} / \mathrm{s}$ is applied, an increment of less than $0.4 \mathrm{~dB}$ is valuable mainly due to a pump current increase.

Figure 12a shows a comparison between BER values of laser pump signal modulation for three different cases (40, 50 , and $60 \mathrm{Mb} / \mathrm{s}$ ). Due to a non-perfect equalization system, tuned for $60 \mathrm{Mb} / \mathrm{s}$ data rates, it can be noticed a power penalty of around $3 \mathrm{~dB}$ from $40 \mathrm{Mb} / \mathrm{s}$ and $60 \mathrm{Mb} / \mathrm{s}$ cases. Error-free conditions have been achieved.

\section{Implementation viability}

In this section, the impact of the implementation of transparency in the MP and CP of core optical networks, from the operator perspective, is discussed.

Fig. 11 Experimental setup for performance evaluation of signaling in PONs
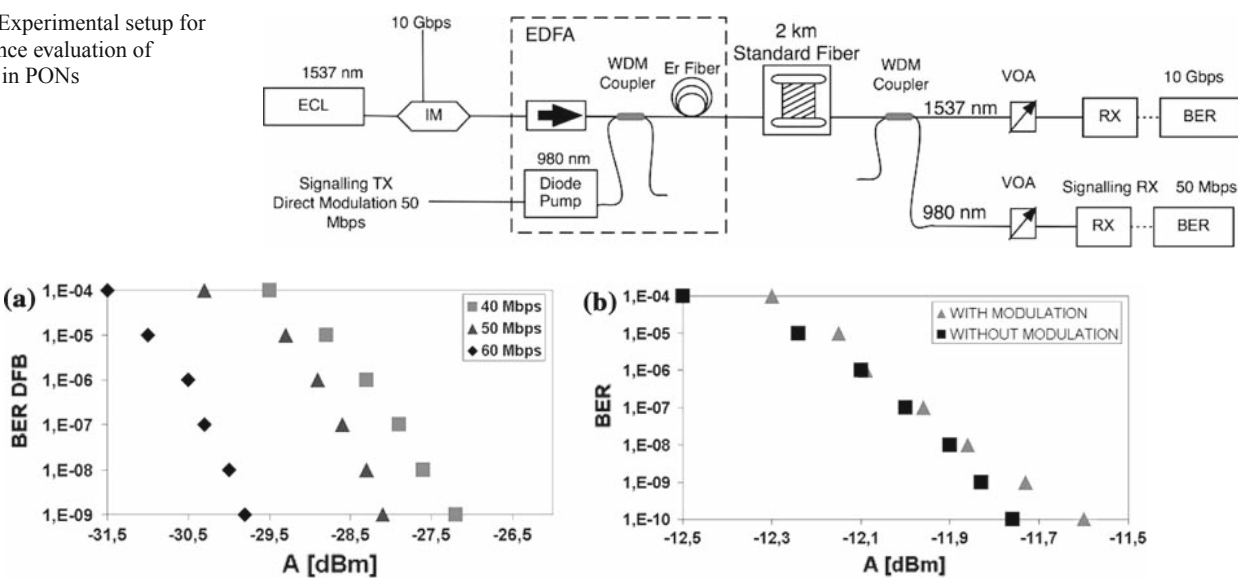

Fig. 12 a BER EDFA diode pump; b BER $10 \mathrm{Gbit} / \mathrm{s}$ modulated signal in two cases: EDFA diode pump modulation ON and OFF 
4.1 Management from the operator point of view

\subsubsection{Performance management}

In opaque networks, each NE management system collects information for quality assessment, NE performance, and traffi control, among others. Transparency implies a decrease of the amount of information collected through $\mathrm{O} / \mathrm{E} / \mathrm{O}$ conversion in nodes, which typically concerns QoT, channel identification and channel overhead bytes. Since QoT is measured on an end-to-end basis, it is not clear if the absence of intermediate BER alike measurement at node sites should be complemented by additional OPM functions. Nevertheless, a communication channel is indispensable for proper network operation, whether it is out of channel (e.g., using an OSC channel [43]) or out of band. If intermediate QoT monitoring is required, we expect it to be very closely correlated to classical BER measurement. Since the latter would only work for a specifi bit rate, modulation format, and vendor, Q-factor monitoring could be an alternative as long as the equivalence with BER is guaranteed. However, both approaches require $\mathrm{CD}$ or power adjustments in order to be accurate. Hence the transparent system design should be adapted accordingly.

\subsubsection{Fault management}

In transparent networks, performance may only be endto-end monitored which has an important impact on fault detection (FD), fault localization (FL), and fault management in general. Moreover, the elaboration of large transparency domains causes vulnerability to fault propagation [44]. As such, system vendors will probably adapt transmission systems and node equipments to avoid it. Again, it is not clear if the use of adequate FL algorithms based on alarm correlation [44] may be sufficient However, convergence time of such algorithms may dramatically increase within transparency domain, and OPM may help to significantly reduce it. In an opaque network, simple parameters commonly measured are the aggregated power in amplifi cation sites, and the channel power at both ends and possibly in equalization sites. In transparent networks the channel power should be monitored in each node crossed, and the other monitoring points should be the same as in opaque networks.

\subsubsection{Configuration management}

Parameters commonly monitored in current point-to-point transmission systems may not be sufficien for both commissioning and provisioning in transparent systems. They are typically: (i) total input/output power of optical amplifier for pump and gain control; (ii) channel power in gain equaliza- tion sites or ROADM; (iii) channel power at transmitter output for laser current control; and (iv) transmitter wavelength drift for wavelength locking. OSNR measurement is not a usual feature, but is mandatory for system commissioning.

Commissioning On the physical point of view, transparent transmission systems have additional engineering constraints due to the aggregation of multiple channels with different histories. This feature is already treated in ROADM systems, and during system design and commissioning stages: all possible paths are tested and validated and no additional OPM is required. In the transparent network scenario, the number of possible paths increases exponentially, so their full validation may not be feasible. Instead, systems may rely on automatic procedures with adequate feedback information. Thus, we may suppose that as OSNR measurement is required for traditional system commissioning, then it should also be for installation of new systems. So, OPM with OSNR monitoring would be required in nodes and used punctually to validate lightpaths.

Provisioning A network configuratio based on NE database information is required to deliver a transparent network capable of capacity provisioning on demand. This could be difficul to implement, since channel information is reduced to partial analogue information, such as wavelength and OSNR. Configuratio also requires using the data communication network. Moreover, the notion of neighbors is not as straightforward as in opaque networks: physical impairments may not allow error-free transmission on a transparent lightpath, although the physical medium exists. Thus, OPM could help to determine physical feasibility of paths, by using a power monitor on each cross-connect ports or perform $\mathrm{Q}$ measurement of a test. However, extensive OPM implementation may be expensive and alternative solutions are to rely on Q estimators based on databases or to fin new procedures based on successive path testing [45].

\subsection{Control plane}

Main functions of the $\mathrm{CP}$ are neighbor discovery, routing, signaling, and local resource management [46]. We estimate that the firs two may be impacted by transparency [47].

Neighbor discovery determines NE connectivity to their neighbors. A link management protocol (LMP) is being standardized by IETF for this purpose. LMP has been designed to accommodate all-optical switches. However, the procedure may not work in service for the case of fully transparent switches. The notion of neighbor may also need to include physical feasibility verification which is not necessary in opaque networks. The short description of LMP in [46] shows that the protocol needs at least power detection at node interfaces, which could be performed by power monitors.

Topology discovery and path computing should only include feasible paths based on (a) the wavelength avail- 
ability related to the RWA problem, and (b) the impairment point of view related to the CB-RWA problem. Q-factor estimation based on database stocking of all necessary parameters needed for the computation [48] is proposed as one way of including both approaches. Still, the physical feasibility problem raises issues like the estimation reliability for time-varying parameters which are considered static, and the complex dynamic update of huge databases. In opaque scenarios, the problem is solved during the installation stage of point-to-point systems.

\subsection{Operator infrastructure constraints}

In the context of dynamic lightpath establishment, the physical feasibility problem can be solved either by relying on estimators and physical parameter databases or on physical tests, as long as the method is reliable. To do so margins are usually set to mask eventual accuracy problems. The resulting trade-off between the amount of margins and the estimation accuracy translates into a cost trade-off between the number of rejected paths due to insufficien quality and the implementation of multiple OPMs. In the following section, we have evaluated this trade-off in the context of France Telecom network, for different scenarios of OPM implementation: (i) test traffi matrices forecasted for 2010, (ii) European size network, (iii) with Table 7, and (iv) with simple estimator.

\subsection{Analysis of OPM needs for QoT computation}

We analyze the impact of OPM on the feasibility estimation reliability, with focus on the effect of more or less precise measurement points in an operational network, rather than on the exact sources of uncertainties which cause estimations errors. The estimator is assumed to be reliable, i.e., a positive estimation guarantees path feasibility. A negative estimation does not mean the opposite, but depends on the confidenc degree of the estimator, which is out of the scope of this paper.

Table 7 Studied network topology

\begin{tabular}{llll}
\hline Network size & 68 nodes & 99 links & \\
Maximum shortest path & 16 hops & $5499 \mathrm{~km}$ & \\
\hline & Average & Minimum & Maximum \\
\hline Link length & $321 \mathrm{~km}$ & $16 \mathrm{~km}$ & $700 \mathrm{~km}$ \\
& $3 \mathrm{spans}$ & $1 \mathrm{span}$ & $11 \mathrm{spans}$ \\
Span length & $77.1 \mathrm{~km}$ & $16 \mathrm{~km}$ & $109 \mathrm{~km}$ \\
Node degree & 2.91 & 2 & 7
\end{tabular}

\subsubsection{Description of the model and network}

We consider an OSNR-based estimator, similar to [49]. In this model, OSNR represents the QoT and some degradations which are translated into penalties on the OSNR value. Penalties are due to nonlinear phase shift (PhiNL) [50], PMD, and $\mathrm{CD}$. Conditions for positive estimation are OSNR $\geq$ $\mathrm{OSNR}_{\min }+$ Penalties and PhiNL $\leq$ PhiNL $_{\max }$ [51]. The exact values of $\mathrm{OSNR}_{\min }$, $\mathrm{PhiNL}_{\max }$, and the maximum allowed amount of penalties depend on the studied transmission equipments. We have restricted the study to classical WDM transmission at $10 \mathrm{Gbit} / \mathrm{s}$ with NRZ modulation format, with performances representative of current ultra long haul commercialized transmission systems. Studies are performed on a European backbone type network with 68 nodes and 99 links. All links are equipped with multiple fibers Table 7 summarizes the main characteristics of the topology.

\subsubsection{Simulation assumptions}

OPM is pointed as a solution to solve parameter estimation inaccuracy and network diversity. To consider the latter we assume that: PMD, CD, and attenuation follow a distribution identical to the existing fibe infrastructure; fibe nonlinear parameters (nonlinear index $n_{2}$, and effective area $A_{\text {eff }}$ ) follow a bounded uniform distribution with standard deviation corresponding to the one observed in the fiel for G.652 fibers and amplifie gain and noise parameters are drawn randomly using a Gaussian distribution.

We focus on power and noise uncertainties introduced by amplifiers Power uncertainty comes mainly from gain ripples of amplifiers Raman tilt, and PDL. Raman tilt and wavelength dependence of fibe loss are supposed to be perfectly corrected by amplifiers Noise uncertainty only depends on amplifie noise ripples. PMD, CD, $n_{2}, A_{\text {eff }}$, and loss uncertainties are neglected. Usually in order to guarantee performances in spite of uncertainties, QoT estimators include margins, whose amount depends on equipment quality. We firs suppose that no margins have been included. Latter, we add margins to the estimator threshold in order to compensate for uncertainties.

To evaluate the impact of power uncertainty on OSNR and PhiNL shift estimations, we simulate an artificia situation, where lightpath performance parameters (OSNR, CD, PMD, and PhiNL) are deduced from off-line measurements, possibly monitored along the path, and used for QoT feasibility estimation. Then we count the number of accepted paths using this estimation. This supposes that the lightpath to monitor exists prior to establishment (e.g., using a test wavelength) or that measurements are collected on neighboring lightpaths having the same route. Situation where no lightpaths are available for monitoring is similar to off-line 
measurement. QoT is estimated for a selection of around 1,000 different paths between $500 \mathrm{~km}$ and $1,500 \mathrm{~km}$ (system reach is around $1,300 \mathrm{~km}$ ) using two distinct network parameter databases: real represents the network parameters state as if they could be measured exactly, whereas measured represents a mix of measurement, monitoring, and estimation of the firs database with accuracy dependent on OPM scenarios. Using the fl wchart illustrated on Fig. 13, we calculate the number of accepted or rejected paths with both databases and identify the main sources of discrepancies. Ideally both databases should lead to the same decision for rejecting a path. Simulation results show instead that estimation based on the measured database leads to wrong decision due to over-estimated (measured Q is over the threshold and real Q is under the threshold) or under-estimated real performances. Performance is guaranteed when no path is over-estimated.

The description of the considered OPM scenarios follows. We assume the existence of a database of all required parameters based on measurement and completed with inline OPM data. The reference scenario uses only standard total input/output power monitoring. Power measurement performed by these OPM is also collected for path QoT computation. The expected average channel power in amplificatio sites is computed through the number of channels crossing the amplifiers For all scenarios, we consider channel power in gain equalization sites or in ROADM, and at transmitter output to be measured by embedded OPMs. Channel wavelength drift is not considered.

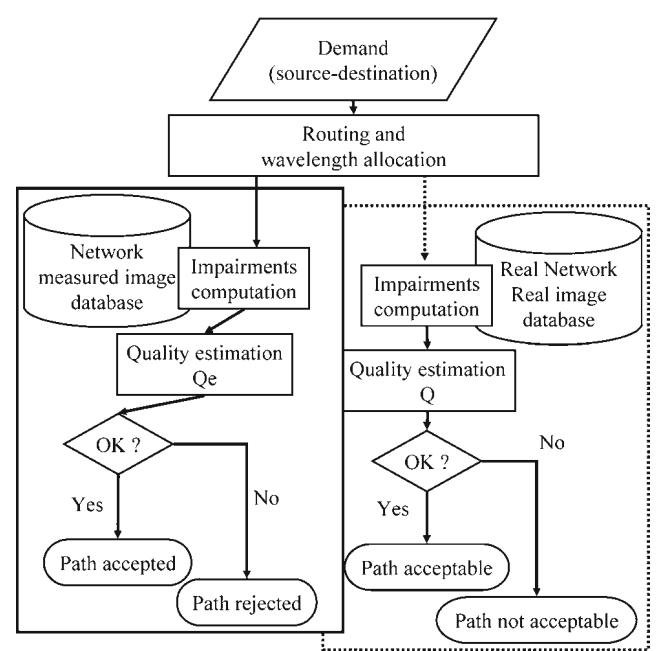

Fig. 13 Simulation set up $\mathrm{fl} \mathrm{w}$ chart
Beside the reference scenario, three optional situations are evaluated: (i) OSNR monitoring at every node input, (ii) channel power monitoring in every amplifie, and (iii) both simultaneously. In all four scenarios we vary measurement accuracy, which is identical for all measurement devices. Averaged values of 40 amplifie configuration were used.

\subsubsection{Simulation results}

Figure 14 shows that all OPM scenarios perform better when OPM accuracy is below $1 \mathrm{~dB}$. Accuracy on channel power has also less impact on the percentage of badly estimated paths, due to the fact that the error is distributed along the paths for OSNR computation. As a result the error is averaged and as the distribution of power uncertainty is randomly distributed around its mean value, the error on computed OSNR tends to zero for a sufficientl high number of measurement points or amplificatio spans. Reversely, when OSNR monitoring is used, only one measurement at the receiver is used for fina QoT estimation and the full inaccuracy is translated on that estimation. Gaussian distribution of amplifie gain ripples is however an optimistic situation. Indeed, operators often select a single equipment type for several links, and then, amplifier on a given link may show similar behavior and gain ripples. Then the error distribution along the path may not be zero in average.

When using both OSNR and channel power monitoring, the percentage of badly estimated paths, when OPM accuracy is $\pm 0.1 \mathrm{~dB}$ is reduced by a factor of 3 . Using OSNR monitoring with a bad accuracy may even perform worse than the reference scenario due to the localized error. Even in the best scenario, there is still a non-negligible percentage of paths that are over-estimated, around $1.5 \%$. This percentage should reach zero in order to guarantee performance.

Figure 15 firs shows that the increase of the margins results in a higher number of under-estimated lightpaths (from around $1 \%$ when no margin is applied to more than

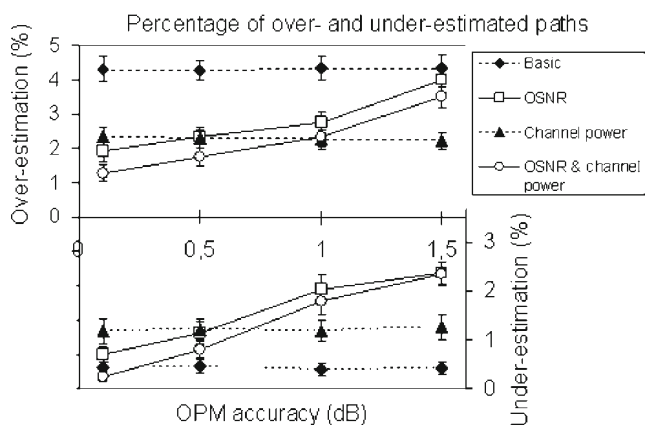

Fig. 14 Percentage of wrong decisions for over- and under-estimations 


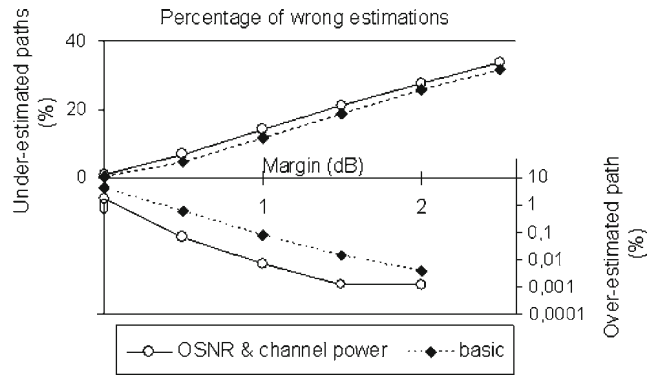

Fig. 15 Percentage of over- and under-estimations as a function of margin

$30 \%$ with $2.5 \mathrm{~dB}$ margin). Figure 15 also shows that the improvement provided by OPM is canceled when margins are used, because bare estimation is slightly optimistic compared to OPM scenarios.

A minimum of $2.5 \mathrm{~dB}$ margin is required to guarantee performance at the expense of a huge amount of rejected paths, which means that route should be either changed to an acceptable path, or one regenerator should be at least used. Thus, a $2.5 \mathrm{~dB}$ margin represents around 350 additional regenerators as compared to a $0 \mathrm{~dB}$ margin.

We conclude that a precise OPM strategy provides better results than bare parameter estimation when power uncertainties are considered. The integration of additional margins for uncertainties allows reducing the percentage of over-estimated lightpaths, but increases the overall number of rejected paths: estimation then performs equally well as monitoring. However, estimation relies on a database, which may not exist due to operational reasons or to a multi-domain configura tion. In this case, monitoring would be the only alternative. If other uncertainties are considered (e.g., PMD [52] or CD uncertainty [53]), and especially if errors are not randomly equally distributed around an average value, an increased amount of margins will be needed, which may be reduced thanks to the use of adequate monitoring.

\section{Conclusion}

The need to explore and identify more suitable M\&C methods to incorporate in WDM networks in general can be solved by taking into account the impact of physical impairments in the network performance, ranging from physical to management layer issues, under an integrated perspective [54].

In this paper we came to the conclusion that impairmentfree or optimum network performance would be difficul to achieve. Instead, stable performance could be a good compromise when dynamic wavelength assignment and routing is considered. To envisage the exact operation conditions prior to the occurrence of new network events on time would imply unfeasible allocation of computational resources and time expenditure. A simpler, more reliable, and efficien solution is to monitor the impact of those events and react cautiously, rather than just using complex, sophisticated, and heavy algorithms to predict everything.

The advantages of this complementary approach are also confirme in Sect. 4 . We concluded that intensive use of different monitoring functions throughout the network would probably have undesired consequences on equipment cost, and would essentially rely on used transmission parameters, like bit rate. However, to rely only on margins would greatly reduce the interest for the implementation of transparent domains. As such, a fair combination of margin, estimation, and monitoring can be a better strategy.

Acknowledgments The work described was carried out with the support of the BONE-project ("Building the Future Optical Network in Europe"), a Network of Excellence funded by the European Commission through the 7th ICT-Framework Programme, and e-Photon/One +, a Network of Excellence funded by the European Commission through the 6th IST-Framework Programme. P. Gravey and T. Loukina would like to thank L. Bramerie (PERSYST platform, UMR FOTON-ENSSAT, Lannion) and E. Pincemin (France Télécom R\&D, Lannion) for making available their $40 \mathrm{Gbit} / \mathrm{s}$ facilities for the evaluation of the freespace OPM prototype and the PERDYN platform for the support of the prototype development. J. A. Lázaro would like to thank Miquel Rius and Victor Polo (UPC) for making available tunable laser and OTDR equipment and Spanish MEC Ramon y Cajal Program. J. A. Lázaro would also like to acknowledge European funded EURO-FOS project support.

\section{References}

[1] Chen, L.K., Cheung, M.H., Chan, C.K.: From optical performance monitoring to optical network management: research progress and challenges (Invited). In: Proceedings of ICOCN (2004)

[2] Saleh, M., Simmons, J.M.: Evolution toward the next-generation core optical network. IEEE/OSA. J. Lightwave Technol. 24(9), 3303-3321(2006). doi:10.1109/JLT.2006.880608

[3] Zang, H., Jue, J.P., Mukherjee, B.: A review of routing and wavelength assignment approaches for wavelength-routed optical WDM networks. SPIE/Baltzer Opt. Netw. Mag. 1(1), 47-60 (2000)

[4] Banerjee, D., Mukherjee, B.: Wavelength routed optical networks: linear formulation resource budgeting tradeoff and a reconfiguratio study. IEEE/ACM Trans. Netw. 8(5), 684-696 (2000)

[5] Yan, S., Ali, M., Deogun, J.: Route optimization of multicast sessions in sparse light-splitting optical networks. IEEE GLOBECOM 4, 2134-2138 (2001)

[6] Mukherjee, B., Ramamurthy, S., Banerjee, D., Mukherjee, A.: Some principles for designing a wide-area WDM optical network. IEEE/ACM Trans. Netw. 4(5), 684-696 (1996)

[7] Ali, M., Ramamurthy, B., Deogun, J.S.: Routing algorithms for all-optical networks with power consideration: the unicast case. In: Proceedings of the 8th IEEE ICCCN, pp. 335-340 (1999)

[8] Banerjee, N., Mehta, V., Pandey, S.: A genetic algorithm approach for solving the routing and wavelength assignment 
problem in WDM networks. In: 3rd IEEE/IEE International Conference on Networking, pp. 70-78 (2004)

[9] Zong, L., Ramamurthy, B.: Optimization of amplifie placement in switch-based optical network. Proc. IEEE ICC 1, 224-228 (2001)

[10] Tomkos, I., Vogiatzis, D., Mas, C., Zacharopoulos, I., Tzanakaki, A., Varvarigos, E.: Performance engineering of metropolitan area optical networks through impairment constraint routing. IEEE Opt. Commun. Mag. 42, 40-47 (2004)

[11] Markidis, G., Sygletos, S., Tzanakaki, A., Tomkos, I.: Impairment aware based routing and wavelength assignment in transparent long haul networks. Optical network design and monitoring. In: Lecture Notes in Computer Science (series), Optical Network Design and Modeling (pp. 48-57). Springer Berlin / Heidelberg (2007)

[12] Brandt-Pearce, J.H., Pointurier, M., Subramaniam, Y.: QoTaware routing in impairment-constrained optical networks. In: Proceedings of GLOBECOM, pp. 26-30, Washington DC (2007)

[13] Ezzahdi, M., Zahr, S., Koubaa, M., Puech, N., Gagnaire, M.: LERP: a quality of transmission dependent heuristic for routing and wavelength assignment in hybrid WDM networks. In: Proceedings of ICCCN, pp. 125-136 (2006)

[14] Deng, T., Subramaniam, S.: Adaptive QoS routing in dynamic wavelength-routed optical networks. Proc. BROADNETS 1, 184-193 (2005)

[15] Kilper, D.C., Bach, R., Blumenthal, D.J., Einstein, D., Landolsi, T., Ostar, L., Preiss, M., Willner, A.E.: Optical performance monitoring. IEEE/OSA. J. Lightwave Technol. 22(1), 294-304 (2004). doi:10.1109/JLT.2003.822154

[16] ITU-T Draft New Recom. G.697. Optical Monitoring for DWDM Systems (2004)

[17] Farrel, A., Vasseur, J. P., Ash, J.: A path computation element (PCE)-based architecture. IETF RFC 4655 (2006)

[18] Jukan, A., Franzl, G.: Path selection methods with multiple constraints in service-guaranteed WDM networks. IEEE-ACM Trans. Netw. 12(1), 59-72 (2004)

[19] Zsigmond, S., Németh, G., Cinkler, T.: Mutual impact of physical impairments and grooming in multilayer networks. In: Proceedings of ONDM, pp. 38-47 (2007)

[20] Winzer, P.J., Essiambre, R.-J.: Advanced optical modulation formats (Invited). Proc. IEEE 94(5), 952-985 (2006). doi:10.1109/ JPROC.2006.873438

[21] Poole, D., Tkach, R.W., Chraplyvy, A.R., Fishman, D.A.: Fading in lightwave systems due to polarization-mode dispersion. IEEE Photon. Technol. Lett. 3(1), 68-70 (1991). doi:10.1109/ 68.68051

[22] Bulow, H., Baumert, W., Schmuck, H., Mohr, F., Schulz, T., Kuppers, F., Weiershausen, W.: Measurement of the maximum speed of PMD fluctuatio in installed fiel fibe. In: Proceedings of OFC/IOOC, pp. 83-85 (1999)

[23] Peterson, N.: Performance monitoring in the next generation of optical networks. In: Proceedings of Photonics in Switching (2006)

[24] ITU-T G.984. 1,2,3,4. GPON recommendations (2004)

[25] Chongjin, X., Kilper, D.C., Moller, L., Ryf, R.: Orthogonalpolarization heterodyne OSNR monitoring insensitive to polarization-mode dispersion and nonlinear polarization scattering. IEEE/OSA. J. Lightwave Technol. 25, 177-183 (2007). doi:10. 1109/JLT.2006.888171

[26] Adams, R., Rochette, M., Ng, T., Eggleton, B.J.: All-optical in-band OSNR monitoring at $40 \mathrm{Gbit} / \mathrm{s}$ using a nonlinear optical loop mirror. IEEE Photon. Technol. Lett. 18(3), 469-471 (2006). doi:10.1109/LPT.2005.863641

[27] Wong, E., Tan, J., Nirmalathas, A.: Novel scheme for simultaneous polarization mode dispersion and optical signal-to-noise ratio monitoring. Proc. ECOC 3, 697-698 (2005)
[28] Liu, N., Zhong, W.-D., Wen, Y.J., Lu, C., Cheng, L., Wang, Y: PMD and chirp effects suppression in RF tone-based chromatic dispersion monitoring. IEEE Photon. Technol. Lett. 18(5), 673-675 (2006)

[29] Park, K.J., Lee, J.H., Young, C.J., Chung, Y.C.A.: Simultaneous monitoring technique for polarization-mode dispersion and group-velocity dispersion. In: Proceedings of OFC, pp. 199-200 (2002)

[30] Inui, T., Komukai, T., Mori, K., Morioka, T.: 160-Gbit/s adaptive dispersion equalization using an asynchronous dispersioninduced chirp monitor. IEEE/OSA. J. Lightwave Technol. 23, 2039-2045 (2005). doi:10.1109/JLT.2005.849878

[31] Maguire, P.J., Bondarczuk, K., Barry, P.P., O’Dowd, J., Guo, W.H., Lynch, M., Bradley, A.L., Donegan, J.F., Folliot, H.: Chromatic dispersion monitoring of $80 \mathrm{Gbit} / \mathrm{s}$ OTDM data signal via two-photon absorption in a semiconductor microcavity. IEEE Photon. Technol. Lett. 19(1), 21-23 (2007)

[32] Yang, J.-Y., Zhang, L., Christen, L.C., Zhang, B., Nuccio, S., Wu, X., Yan, L.-S., Yao, S., Willner, A.E.: Polarization-mode-dispersion monitoring for phase-modulated signals using DGD-generated interferometric filte. IEEE Photon. Technol. Lett. 20(2), 150-152 (2008). doi:10.1109/LPT.2007.912505

[33] Willner, A.E., Nezam, S.M.R.M., Yan, L., Zhongqi, P., Hauer, M.C.: Monitoring and control of polarization-related impairments in optical fibe systems. IEEE/OSA. J. Lightwave Technol. 22, 106-125 (2004). doi:10.1109/JLT.2003.822556

[34] Lizé, Y.K., Christen, L., Yang, J.-Y., Saghari, P., Nuccio, S., Willner, A.E., Kashyap, R.: Independent and simultaneous monitoring of chromatic and polarization-mode dispersion in OOK and DPSK transmission. IEEE Photon. Technol. Lett. 19(1), 3-5 (2007). doi:10.1109/LPT.2006.888039

[35] Morawski, R.Z., Miekina, A., Barwicz, A.: Curve-fittin algorithms versus neural networks when applied for estimation of wavelength and power in DWDM systems. IEEE Trans. Instrum. Meas. 54(5), 2027-2032 (2005). doi:10.1109/TIM.2005.853350

[36] Lazaro, J.A., Bock, C., Polo, V., Martinez, R.I., Prat, J.: Remotely amplifie combined ring-tree dense access network architecture using reflect ve RSOA-based ONU. J. Opt. Netw. 6(6), 801-807 (2007). doi:10.1364/JON.6.000801

[37] Lazaro, J.A., Prat, J., Chanclou, P., Beleffi G.M.T., Teixeira, A., Tomkos, I., Soila, R., Koratzinos, V.: Scalable extended reach PON (Invited). In: Proceedings of OFC/NFOEC, OThL2 (2008)

[38] Polo, V., Ausiro, A., Prat, J., Junyent, G.: GCSR laser frequency drift compensation using optimized current waveform on one single electrode. Proc. ICTON, 2, 17-20, We.A1.5 (2005)

[39] Kazmierski, C., Chanclou, P., Lazaro, J.A.: Advanced component technologies for colourless access networks. (Invited), In: Proceedings of SPIE, p. 6782 (2007)

[40] Gnauck, H., Cimini, L.J., Jr., Stone, J., Stulz, L.W.: Optical equalization of fibe chromatic dispersion in a 5-Gbit/s transmission system. IEEE Photon. Technol. Lett. 2(8), 585-587 (1990). doi: $10.1109 / 68.58056$

[41] Vázquez, C., Vargas, S.E., Sánchez Pena, J.M.: Sagnac loop in ring resonators for tunable optical filters IEEE/OSA. J. Lightwave Technol. 23(8), 2555-2567 (2005). doi:10.1109/JLT.2005. 850793

[42] Vargas, S.E., Vázquez, C.: Synthesis of optical filter using sagnac interferometer in ring resonator. IEEE Photon. Technol. Lett. 19(23), 1877 (2007). doi:10.1109/LPT.2007.908735

[43] Maeda, M.: Management and control of transparent optical networks. (Invited). IEEE J. Sel. Areas Commun. 16(7), 1008-1023 (1998). doi:10.1109/49.725174

[44] Mas, C., Tomkos, I., Tonguz, O.K.: Failure location algorithm for transparent optical networks. IEEE J. Sel. Areas Commun. 23(8), 1508-1519 (2005). doi:10.1109/JSAC.2005.852182 
[45] Cugini, F., Andriolli, N., Valcerenghi, L., Castoldi, P.: A novel signaling approach to encompass physical impairments in GMPLS networks. Procedings of GLOBECOM Workshops pp. 369-373 (2004)

[46] Bernstein, G., Rajagopalan, B., Saha, S.: Optical Network Control: Architecture, Protocols \& Standards. Addison-Wesley, Reading, MA (2004)

[47] Bernstein, G.: Optical network control - concepts, standardization and interoperability. In: Proceedings of ECOC, We.1.2.1. (2004)

[48] Ali, M.E.-D., Cosaque, D., Tancevski, L.: Enhancements to multi-protocol lambda switching to accommodate transmission impairments. Proc. GLOBECOM 1, 70-75 (2001)

[49] Lavigne, B., Leplingard, F., Lorcy, L., Almefrezol, E., Antona, J.-C., Zami, T., Bayart, D.: Method for the determination of a quality of transmission estimator along the lightpaths of partially transparent networks. In: Proceedings of ECOC, 8.5.2 (2007)

[50] Morea, A.: Etude des réseaux optiques translucides: évaluation de leur faisabilité technique et de leur intérét économique. Doctorat Informatique et Réseaux. INFRES, ENST. Paris (2006)

[51] Antona, J.-C., Bigo, S., Faure, J.-P.: Nonlinear cumulated phase as a criterion to assess performance of terrestrial WDM systems. In: Proceedings of OFC, pp. 365-367 (2002)

[52] Hamel, A., Gavignet, P., Salann, S., Poirrier, J.: Design tradeoff for high PMD routes in installed transmission systems. In: Proceedings of OFC/NFOEC, OFL4 (2006)

[53] Leplingard, F., Zami, T., Morea, A., Brogard, N., Bayart, D.: Determination of the impact of a quality of transmission estimator margin on the dimensioning of an optical network. In: Proceedings of OFC/NFOEC, OWA6 (2008)

[54] Tomkos, I., Sygletos, S., Tzanakaki, A., Markidis, G.: Impairment constraint based routing in mesh optical networks. (Invited). In: Proceedings of OFC/NFOEC, OWR1 (2008)

\section{Author Biographies}

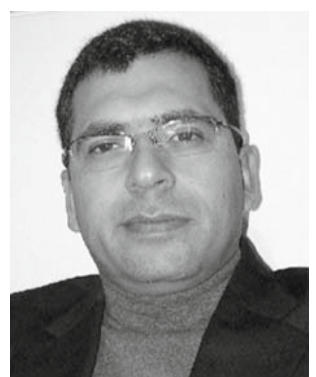

A. Teixeira was born in Portugal, on November 17, 1970. He received the Licenciatura degree in Electronics Engineering and Telecommunications, in July of 1994 and the $\mathrm{PhD}$ degree in Electrical Engineering, in 1999 all from the University of Aveiro, Portugal. He is currently an Assistant Professor at the Department of Electronics, Telecommunications and Informatics of the University of Aveiro and researcher at the Institute of TelecommunicationsAveiro. His research interests include DWDM optical networks, dispersion compensation, fibe Bragg gratings, and radio over fibe technologies. He is member of the Institute of Electrical and Electronics Engineers (IEEE) and of the Optical Society of America (OSA)

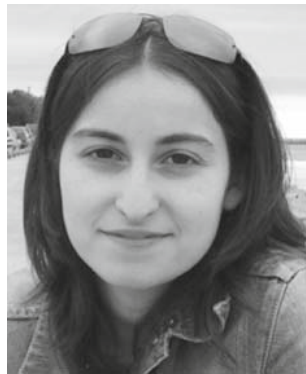

L. Costa was born in Portugal, on August 1, 1984. She received the Licenciatura degree in Electronics Engineering and Telecommunications, in July of 2007. Since then she is working in the Instituto de Telecomunicções in Aveiro, Portugal. Her research interests include semiconductor optical amplifier technologies and applications and optical monitoring techniques. She has been participating in FP6 ePhotonOne+ and FP7 SARDANA and EURO-FOS EU funded projects.

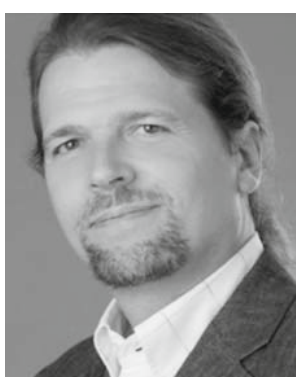

G. Franzl received the academic degree Dipl.-Ing. in Electrical Engineering, specialized in Communications Engineering and Information Processing, from the Vienna University of Technology, Austria, in 2002. From February 2004 till June 2007 he was employed firstl as R\&D assistant lately as technical product manager at MEDIORNET $\mathrm{GmbH}$, a startup company in Vienna, closed in June 2007, developing a fibe -based content distribution network (X-Switch) for the professional broadcast industry. Since 2003 he contributes to the Institute of Broadband Communications at the Vienna University of Technology within his $\mathrm{PhD}$ program participating in several national and EU funded projects. His current research interests are in the area of optical networks and traffi engineering, focusing on QoS sensitive routing schemes and end-to-end performance evaluation based on queuing models.

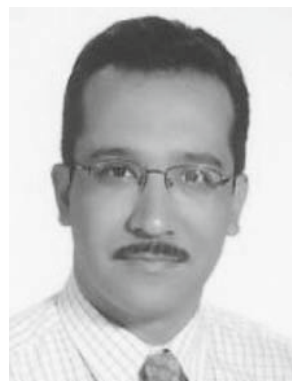

S. Azodolmolky received his computer hardware (B.Eng.) degree from Tehran University in Iran in 1994 and his firs master degree (M.Eng.) in computer architecture from Azad University, in 1998. He has worked with the Data Processing Iran (ex-IBM), as a Systems Engineer and Senior R\&D Engineer during 1992-2001. $\mathrm{He}$ received his second M.Sc. degree with distinction from the Information Networking Institute of the Carnegie Mellon University, in 2006. In August 2007 he joined Athens Information Technology as a researcher, while also pursuing a $\mathrm{PhD} \mathrm{He}$ is a professional member of ACM and a student member of IEEE. 


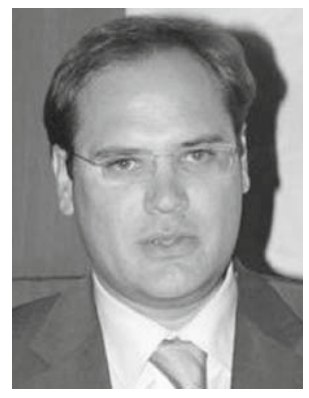

I. Tomkos has the rank of Full Professor at Athens Information Technology Center, serves as its Associate Dean (since 2004), and is an Adjunct Faculty at the Information Networking Institute of Carnegie-Mellon University, USA. In the past (1999-2002) he held a senior scientist position at Corning Inc. USA. He joined AIT in 2002 where he founded and serves as the Head of the "High Speed Networks and Optical Communication (NOC)" Research Group that participates in many EU funded research projects (including 5 running FP7 projects) in which Dr. Tomkos is representing AIT as Principal Investigator and has a consortium-wide leading role (e.g. Project Leader of the EU ICT STREP project DICONET, Technical Manager of the EU IST STREP project TRIUMPH, Chairman of the EU COST 291 project, WP leader). Dr. Tomkos has received the prestigious title of "Distinguished Lecturer" of IEEE Communications Society for the topic of transparent optical networking. Together with his colleagues and students he has authored more than 200 peer-reviewed articles and his work has received over 600 citations. Dr. Tomkos has served as the Chair of the International Optical Networking Technical Committee of IEEE Communications Society and a member of the IEEE ComSoc's Technical Activities Council. He is currently the Chairman of the OSA Technical Group on Optical Communications and the Chairman of the IFIP working group on "Photonic Networking". He has been General Chair, Technical Program Chair, and member of the steering/organizing committees for the major conferences (e.g. OFC, ECOC, IEEE GlobeCom, IEEE ICC, etc.) in the area of telecommunications/networking (more than 50 conferences/workshops). In addition he is a member of the Editorial Boards of the IEEE/OSA Journal of Lightwave Technology, the OSA Journal of Optical Networking, the IET Journal on Optoelectronics, and the International Journal on Telecommunications Management.

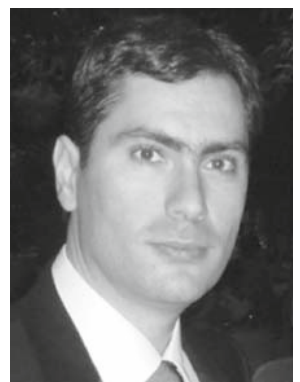

K. Vlachos received his Dipl.-Ing. degree in electrical and compute engineering from the National University of Athens (NTUA), Greece, in 1998 and his Ph.D. in electrical and computer engineering, also from NTUA, in 2001. From 1997 to 2001 he was a senior research associate in the Photonics Communications Research Laboratory (ICCS/NTUA). In April 2001 he joined Bell Laboratories, Lucent Technologies, working on behalf of the Applied Photonics Group. Prof. Vlachos conducted research on high-speed optical networks and DWDM transmission techniques. During 2003, he joined the National Regulation Authority of Telecommunication and Postal Service of Greece (EETT), where he served as a scientifi advisor for various techno-economic issues for the promotion of broadband technologies. Since 2003, he was also a member of Computer Engineering laboratory of Technical University of Delft and since 2005, a faculty member of Computer Engineering and Informatics Department of Uni- versity of Patras, Greece. His research interests are in the areas of highspeed protocols and technologies for broadband, high-speed networks, optical packet/burst switching, and grid networks. Prof. Vlachos has participated in various research project funded by the European Commission (IST-STOLAS, IST-PRO3, ESPRIT-DOALL, e-photon/ONe+, IST-PHOSPHROUS, ICT-BONE $\kappa \alpha \iota$ ICT-DICONET). Prof. Vlachos is a member of IEEE and the Technical Chamber of Greece and he periodically acts as a scientifi reviewer for the General Secretariat for Research and Technology of Greece (GSRT) as well as for the European Commission and the Netherlander Organization for Scientifi Research, Technology Foundation. Prof. Vlachos is the (co) author of more than 70 journal and conference publications and holds fi e (5) patents.

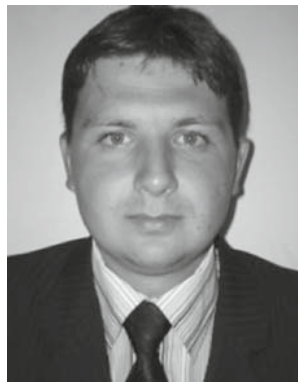

S. Zsigmond has received M.Sc. ('04) degree in physics from the Budapest University of Technology and Economics (BME), Hungary, where he is currently consultant manager at the Department of Telecommunications and Media Informatics. His research interests focus on all optical networks, physical effects of the optical networks, PMD, optical switching architectures, impairments constraint-based routing. $\mathrm{He}$ is author of several refereed scientifi publications. He has been involved in numerous related European and Hungarian projects including COST 291, NoE e-Photon/ONe, and $\mathrm{NoE}$ e-Photon/ONe+; CELTIC PROMISE; NKFP.

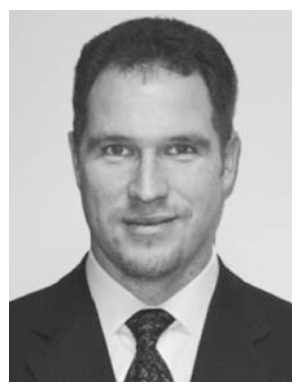

T. Cinkler has received M.Sc. ('94) and $\mathrm{PhD}\left({ }^{\prime} 99\right)$ degrees from the Budapest University of Technology and Economics (BME), Hungary, where he is currently associate professor at the Department of Telecommunications and Media Informatics. His research interests focus on optimization of routing, traffi engineering, design, configuration dimensioning and resilience of IP, Ethernet, MPLS, ngSDH, OTN, and particularly of heterogeneous GMPLS-controlled WDM-based multilayer networks. He is author of over 180 refereed scientifi publications and of 4 patents. He has been involved in numerous related European and Hungarian projects including ACTS METON and DEMON; COST 266, 291, 293; IP NOBEL I and II and MUSE; NoE e-Photon/ONe, e-Photon/ONe+ and BONE; CELTIC PROMISE and Tiger II; NKFP, GVOP, ETIK; and he is member of ONDM, DRCN, BroadNets, AccessNets, IEEE ICC and Globecom, EUNICE, CHINACOM, Networks, WynSys, ICTON, etc. scientifi and Programm Committees. $\mathrm{He}$ has been guest editor of a Feature Topic of the IEEE ComMag and reviewer for many journals and conferences. 


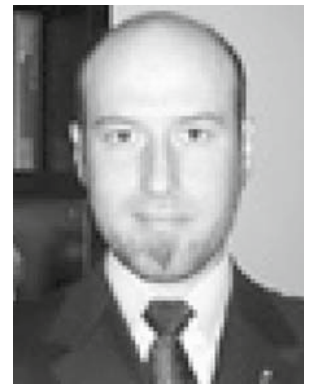

G. Tosi-Beleffi has an experience of 8 years in optical technologies, devices, architectures, systems and subsystems, wired and wireless, for the Metro and Access telecommunication sectors as part of the Next Generation Broadband Network. Dr. Tosi Beleff has solid skills in scientifi research and management activities, in coordination activities at EU level with participation at EU co funded projects and COST actions. Participation to FP5 ATLAS, FP6 ePhotonOne/ePhotonOne+, ,FP7 BONE, and SARDANA projects. Italian Delegate of COST MP0702 on integrated devices. Didactics performed with courses and seminars at Italian and foreign Universities. Member of IEEE Leos and OSA international societies. TPC member of IEEE ICTON, IEEE ICT, and CONTEL international conferences. Member of Euro-Japan ICT and Euro-SouthKorea communities. Chairman of IEEE ICTON 2007 conference and Chairman of Market in TLC session (IEEE ICTON Conference). Dr. Tosi Beleff is author of 18 publications on international journals and of more than 40 publications on national and international conferences. Patent on all optical regeneration (WO 2005/109080 A1). Interactions and joint activities/missions performed in foreign countries like Portugal, Japan, Czech Republic, Greece, Spain, UK

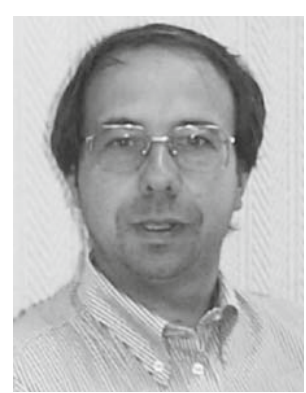

P. Gravey graduated from Ecole Polytechnique (PalaiseauFrance) in 1978, from Ecole Nationale Supérieure des Télécommunications (Paris - France) in 1980 and received a Diplôme d'Etudes Approfondies in Optics (Orsay-France), also in 1980 . He then joined the Centre National d'Etudes des Télécommunications (now Orange Labs) in Lannion to work on holographic techniques and materials applied to optical interconnections. Between 1993 and 1997, he was in charge of the "Photonic Switching Processors" department, and then conducted a project on Optical Cross-connects. He was also involved in European Projects on Optical Switching and Optical Packet Switching. In 2000, he joined the Optics Department of TELECOM Bretagne and co-founded the Optogone company in 2001, which developed liquid crystal-based devices for WDM applications. He returned to the Optics department in 2005. His present research interests include access and optical packet networks and monitoring. He authored or co-authored more than 80 publications or communications and 8 patents.

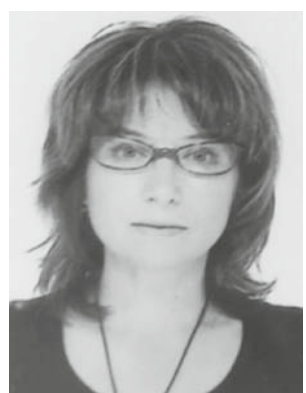

T. Loukina graduated from Kazan State University (Russia) in 1984. During 15 years she worked on diffractive holographic optical components and volume holography: design, fabrication, test benches ( $\mathrm{PhD}$ on optical holographic elements, 1999, Moscow) in State Institute of Applied Optics (Russia). Since 1999 she works in optical communications domain (Ph.D. on diffractive optics and spectral equalization for DWDM systems in TELECOM Bretagne, 2003, Brest). Between 2002 and 2004 she was with Optogone SA where she brought a major contribution to the development of a free-space Dynamic Gain Equalizer. Since 2005, she is working on the Perdyn platform, dedicated to advanced WDM functions and access networks and she led a project on a free-space Optical Performance Monitor. Her research interests include holography and optical monitoring. She authored or co-authored more than 25 publications or communications.

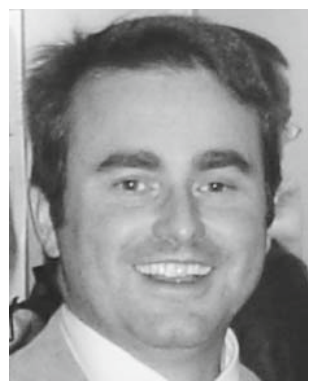

J. A. Lázaro received the M.Sc. degree in physics in 1993 and the $\mathrm{PhD}$ degree from the University of Zaragoza (Spain) in 1999 for his research work in Erbium Doped Waveguide Amplifier (EDWA). He is currently Ramony-Cajal Researcher at the Optical Communications Group of the Department of Signal Theory and Communications of the Universitat Politácnica de Catalunya (UPC), teaching at the ETSETB Engineering School of UPC in Barcelona, and the Master in Photonics "PhotonicsBCN". Prior to this position, he was Senior Researcher at the Optical Transmission and Broadband Technologies Laboratory of the Aragon Institute for Engineering Research (I3A) in Huesca (Spain) and R\&D Engineer in ALCATEL in Stuttgart (Germany) at the Department of Passive Optical Components (2000-2002), and at the Department Optical Transmission Systems (2002-2004). He has been participating in several European projects (e-Photon/One, BONE, EURO-FOS, and SARDANA) on optical transmission, monitoring, subsystems, and access networks. 


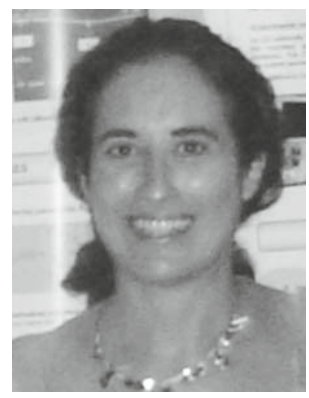

C. Vazquez (M'99-SM'05) was born in Madrid, Spain, on May 1968. She received the M.S. degree in Physics (Electronics) in 1991 from Complutense University of Madrid, and her Ph.D. degree at Telecommunications Engineering School in 1995 from Polytechnic University of Madrid (UPM). In 1991 she enjoys a fellow at TELECOM (Denmark), working in erbium doped fibe amplifiers From 1992 to October 1995 she worked at Optoelectronics Division of "Telefnica Investigacin y Desarrollo". She was involved in III/V integrated optics devices. In October 1995, she joined Carlos III University of Madrid where she is currently working as an Associate Professor, leader of the Photonics Applications Group, Vice-rector of Quality, Infrastructures and Environment, and has been Head of the Electronics Technology Department

for 3 years. Her current work includes optical signal processing, ring resonators, plastic optical fibers broadband access networks, RoF systems, filters switches, fibe sensors design of fibe optics, LC and integrated optic devices and their application to optical communications, instrumentation and sensor networks. She has published more than 140 papers in journals and conferences. She won the extraordinary doctorate prize of UPM in 1995 and biannual prize for young professor at UC3 M in 2004. She participates as leader and researcher in Spanish and European Research Projects in Photonics. She is a member of SPIE, OSA, and SEO.

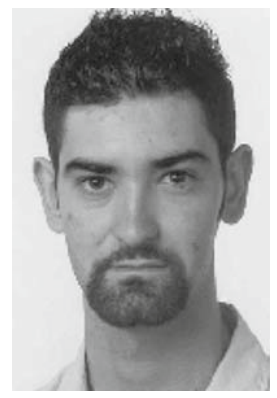

J. Montalvo was born in Madrid, Spain, on May 1979. He received his M.S. Degree in Telecommunication Engineering in January 2003 from Politechnic University of Madrid (UPM) and obtained his PhD Degree in Electrical, Electronics and Robotics Engineering in April 2008 from Carlos III University of Madrid (UC3 M). As a member of the Displays and Photonics Applications Group at UC3 M, his research work is involved in optic filte and devices design and characterization for Coarse and Dense Wavelength Division Multiplexed (WDM) networks for sensors and broadband access. Currently he is also working in the Telecommunications Industry on Optical Broadband Networks for Telefnica Research and Development.

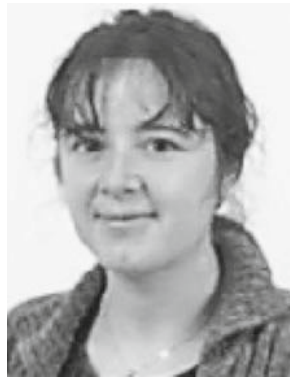

E. Le Rouzic received the telecommunications degree from Ecole Nationale Supérieure des Télécommunications de Bretagne, France, the M.Sc. degree from the University College London, U.K., in 1996, and the $\mathrm{PhD}$ degree in electronics and communications from Ecole Nationale Supérieure des Télécommunications, France, in 1999. She joined France Telecom R\&D in Lannion in 2000, where she has been working on wavelength division multiplexing (WDM) networks, optical functions, optical transmission, and translucent networks. She is involved in national and European projects dealing with optics and authored about 25 national or international papers or communications. 